\title{
Impact of Mooring Lines Dynamics on the Fatigue and Ultimate Loads Computed with IEC 61400-3 Guideline for Three Offshore Floating Wind Turbines
}

\author{
Jos'e Azcona, David Palacio ${ }^{1}$, Xabier Munduate, Leo Gonzalez, Tor Anders Nygaard
}

\begin{abstract}
The calculation of loads for floating offshore wind turbines requires time-domain integrated simulation tools where most of physical concepts involved in the system dynamics are considered. The loads at the different components are used for the structural calculation and influence the design noticeably. This study quantifies the influence of mooring dynamic models on the calculation of fatigue and ultimate loads with integrated tools and compares its performance with lower computational cost mooring models as the Quasi-Static. Three platforms representing the principal typologies (spar, semisubmersible and TLP) were assumed to be installed at the same $200 \mathrm{~m}$ depth location in the Irish coast. For each platform, the fatigue and ultimate loads were computed with an integrated floating wind turbine simulation code using both, a Quasi-Static and a fully dynamic moorings model. More than 20,000 load cases were launched and postprocessed following the IEC 61400-3 guideline and fulfilling all the conditions that a certification entity would require to an offshore wind turbine designer. The results showed that the impact of mooring dynamics on the loads depends on the platform typology and the element considered: blade, shaft, tower or mooring lines. Mooring dynamics have particular impact on the loads of the TLP concept and in the tension of the mooring lines independently of the platform design. Platforms with the fairleads of the moorings located a long radius from the platform center and platforms with natural frequencies inside the wave spectrum are also particularly sensitive to the mooring dynamics. Copyright (c) 2010 John Wiley \& Sons, Ltd.
\end{abstract}

\section{KEYWORDS}

offshore wind turbine; mooring line; dynamic; coupled codes; loads calculation; standards

\author{
Correspondence \\ José Azcona \\ National Renewable Energy Centre, CENER \\ Ciudad de la Innovación 7, 31621 Sarriguren, Navarra, Spain \\ Telephone: +34948252800 \\ FAX: +34 948270774 \\ E-mail: jazcona@cener.com \\ Received...
}

\section{INTRODUCTION}

The load calculation of floating offshore wind turbine requires time-domain simulation tools taking into account all the phenomena that affect the system such as aerodynamics, structural dynamics, hydrodynamics, control actions and the mooring lines dynamics. These effects present couplings and are mutually influenced. The computational tools able to compute these coupled effects are called integrated or coupled codes.

The fatigue and ultimate loads provided by integrated tools are used for the structural design of the different components of the wind turbine, consequently treated as inputs for the structural computation performed by Finite Elements Methods 
(FEM). The level of loads can have an important influence over the design, impacting on the optimization of the components and the final cost of the floating wind turbine.

The calculation of the design loads for floating wind turbines requires the consideration of a complete set of load cases describing all the situations that the system can experience. These cases are described in guidelines of certification entities and include different operation conditions (idling, power production, stops...), wind and wave conditions, gusts, control failures, misalignments, etc. The total number of cases to be simulated is typically of several thousands. A compromise between the accuracy of the models for the prediction of the loads and the computational cost is required. In this context it is important to evaluate when models, that include more complex physics but require more CPU time, influence the load levels and when their effect is negligible and simpler and more cost efficient tools can be used in the simulations without loss of accuracy.

The mooring lines of an offshore floating wind turbine connect the platform with the seabed, holding the structure in the desired location. In designs such as the Tension Leg Platforms (TLP) mooring lines also contribute to the stability of the system. Consequently, the influence of mooring lines on the global dynamics of a floating wind turbine are an important factor on the motion of the system and the loads of the different components [1].

Many integrated codes for floating wind turbines include simplified methods for the simulation of the moorings are very computationally efficient but do not consider the lines dynamics. The Quasi-Static model is a simplified approach that consists in the resolution of the static equations of the catenary at every time step of the simulation, given the position of the line-platform attachment. This method neglects the inertial effects and also the hydrodynamic drag produced by waves, currents or the movements of the line. On the other hand, dynamic models consider effects as inertia, added mass or hydrodynamic drag, but they demand higher computational effort. Several numerical formulations such as the Finite Elements Method (FEM), the Finite Difference Method or Multi-Body models can solve the dynamics of the line. The Lumped Mass model can be considered a variation of the FEM approach, where the mass of the elements is concentrated in the element adjacent nodes. Many references describe the Quasi-Static and dynamic formulations of mooring lines, being [2] and [3] clear examples.

Some studies have been already published relating the influence of the mooring lines dynamics on the loads of floating wind turbines. One of the most complete is presented in [4], where simulations using a Quasi-Static mooring lines model and a dynamic model are compared for three different floating wind turbines: the OC3-Hywind spar, the ITI Energy barge and the MIT/NREL TLP. The study concludes that mooring dynamics can affect the fatigue and ultimate loads and the adequacy of Quasi-Static model is dependent on the support configuration, being well suited for spars with natural periods below the peak wave period. A previous study by Kallesøe et al. [5] compared simulations of the OC3-Hywind platform using Quasi-Static and dynamic mooring models, concluding that calculation of loads with Quasi-Static approach is conservative and the use of mooring dynamics can affect the resulting fatigue tower loads. Matha et al. [6] also performed a comparative study of fatigue equivalent loads for the OC3-Hywind spar based on a single load case computed with a Quasi-Static and a Multi-Body dynamic model. The turbine loads were slightly affected, but significant differences in the fairlead equivalent tensions were found. They also concluded that the importance of dynamic effects of the lines have to be further investigated with a comprehensive analysis based on the requirements and load cases specified in the guidelines. Masciola et al. [7] compared scaled experimental data of the OC4 semisubmersible platform with coupled simulations using Quasi-Static and dynamic moorings model. They concluded that the lines dynamics have a limited importance in the motions of the platform, but are relevant for the calculation of the lines tension.

\section{OBJECTIVE AND METHODOLOGY}

In this work, we have carried out an extensive assessment of the effect of mooring dynamics on the fatigue and ultimate loads of different floating wind turbines concepts. The loads were computed following the floating wind turbines IEC 61400-3 Edition 1 guideline [8].

The objective of our work is to identify in which conditions and for which platform concepts the mooring dynamic effects have influence on the simulation results. The influence of the lines dynamic effects over the level of fatigue and ultimate loads of the different wind turbine components is quantified providing future designers information for the selection of the adequate mooring lines model.

Three platforms (semisubmersible, spar-buoy and TLP), representing the three main methods to achieve stability were considered. In order to obtain comparable results, the three concepts are designed for a sea depth of $200 \mathrm{~m}$ and they are assumed to be at the same location supporting the same $5 \mathrm{MW}$ wind turbine.

For each of these platforms, the load cases defined by the IEC 61400-3 Edition 1 guideline [8] were simulated using the FAST code with both, the Quasi-Static moorings model and the OPASS dynamic model [?]. Almost all the load cases defined by the standard were computed, fulfilling similar requirements that a certification entity would request to a manufacturer. More than 3500 cases for each platform and mooring model were launched in a cluster. The fatigue and 
ultimate loads for each platform concept and each mooring model were postprocessed and the results compared.

As was mentioned in the introductory Section 1, Hall et al. compared coupled simulations using a Quasi-Static and a dynamic model for three different floating platforms [4]. Nevertheless, there are several important differences between Hall's and our study, that we would like to highlight to better understand the conclusions of our work:

- Hall computed the fatigue equivalent loads for a very limited number of individual cases. In our study, fatigue equivalent loads are computed based on all the load cases requested by the guideline and their contribution to the fatigue load is weighted based on their importance on the turbine lifetime.

- Similarly, Hall computed the extreme loads for a limited number of cases. In our study, all the load case groups requested by the guidelines are included.

- Hall did not compute the environmental data from a real location as performed in this study.

- The ITI barge is one of the platform concepts analyzed in Hall's study. Instead, we used a semisubmersible, which is also a buoyancy stabilized concept, but we consider it is closer to a industrial design.

- The NREL/MIT TLP is the platform design used in Hall's study to characterize the behaviour of platforms with taut moorings. The TLP concept used in our study has less draft (19.72 $\mathrm{m}$ instead of $47.89 \mathrm{~m})$ and is much lighter, not using ballast to increase stability.

- The three platforms used in Hall's study are located at different sea depths (320 m, $150 \mathrm{~m}$ and $200 \mathrm{~m})$ which could affect the importance of dynamic effects. In this study all are assumed to be in the same location and water depth of $200 \mathrm{~m}$.

\section{THE OPASS CODE}

The OPASS code (Offshore Platform Anchorage System Simulator) is a Lumped Mass model developed by CENER (the Spanish National Renewable Energy Centre) for the simulation of non-linear mooring dynamics. The physical model consists of an slender line with constant circular section and considers three translational degrees of freedom at each node. It takes into account the effect of inertia, hydrodynamic added mass, gravity, hydrostatics, wave kinematics, tangential and normal hydrodynamic drag, axial elasticity and structural damping. The code neglects the bending stiffness, being suitable for the simulation of chains. The contact and the friction between the line and the seabed is also included.

A verification of the OPASS code against computations of 3DFloat code [10] was successfully accomplished in [9]. Afterwards, a verification of OPASS coupled with FAST was satisfactorily carried out within the IEA Annex 30 benchmark (OC4) [11]. Finally, an experimental validation has been completed against test data of a submerged chain generated at the Ėcole Centrale de Nantes (ECN) wave tank in France.

In this study, OPASS was coupled with FAST [2] to compute the fatigue and ultimate loads of three different concepts of floating wind turbines including the mooring lines dynamics. For the simulation of the load cases with the Quasi-Static mooring approach, the default mooring model of the FAST code was used.

\section{FLOATING WIND TURBINES SELECTED}

The three platform designs selected for this study are the UMaine Hywind spar [12], the OC4 DeepCwind semisubmersible [13] and the UMaine TLP [14] and are shown in Figure 1. The description of the three platforms is public and all of them support the NREL offshore 5MW baseline wind turbine [15].

The UMaine Hywind spar floating platform is an adaptation for $200 \mathrm{~m}$ sea depth by the University of Maine of the OC3-Hywind concept for $320 \mathrm{~m}$ depth used in the IEA Annex 23 project (also known as OC3 project) [12]. The concept used in the OC3 project was based on the publicly available information of the Hywind project. The draft of the UMaine Hywind spar platform is $120 \mathrm{~m}$ below sea water level (SWL). The basic shape of the substructure consists of two cylindrical regions connected by a tapered conical region. The cylinder diameter above the taper $(6.5 \mathrm{~m})$ is more slender than the cylinder diameter below $(9.4 \mathrm{~m})$ to reduce the hydrodynamic loads near the free surface. The lower part of the platform is ballasted to decrease the center of gravity $(\mathrm{CM})$ below the center of buoyancy $(\mathrm{CB})$, increasing the metacentric height and the restoring arm that appears when the platform pitches.

The semisubmersible concept was created within the DeepCwind project [17] and used as a benchmark model in the IEA Annex 30 project [13] (also known as OC4 project). It consists of a main column attached to the tower, and three offset columns that are connected to the main column with pontoons and cross members. The buoyancy of the offset columns increases the water plane inertia and provides stability to the platform. The draft of the platform is $20 \mathrm{~m}$ and the distance between the external columns is $50 \mathrm{~m}$.

The UMaine TLP was created by the University of Maine [14] inspired by the Glosten Associates design [18]. The draft 

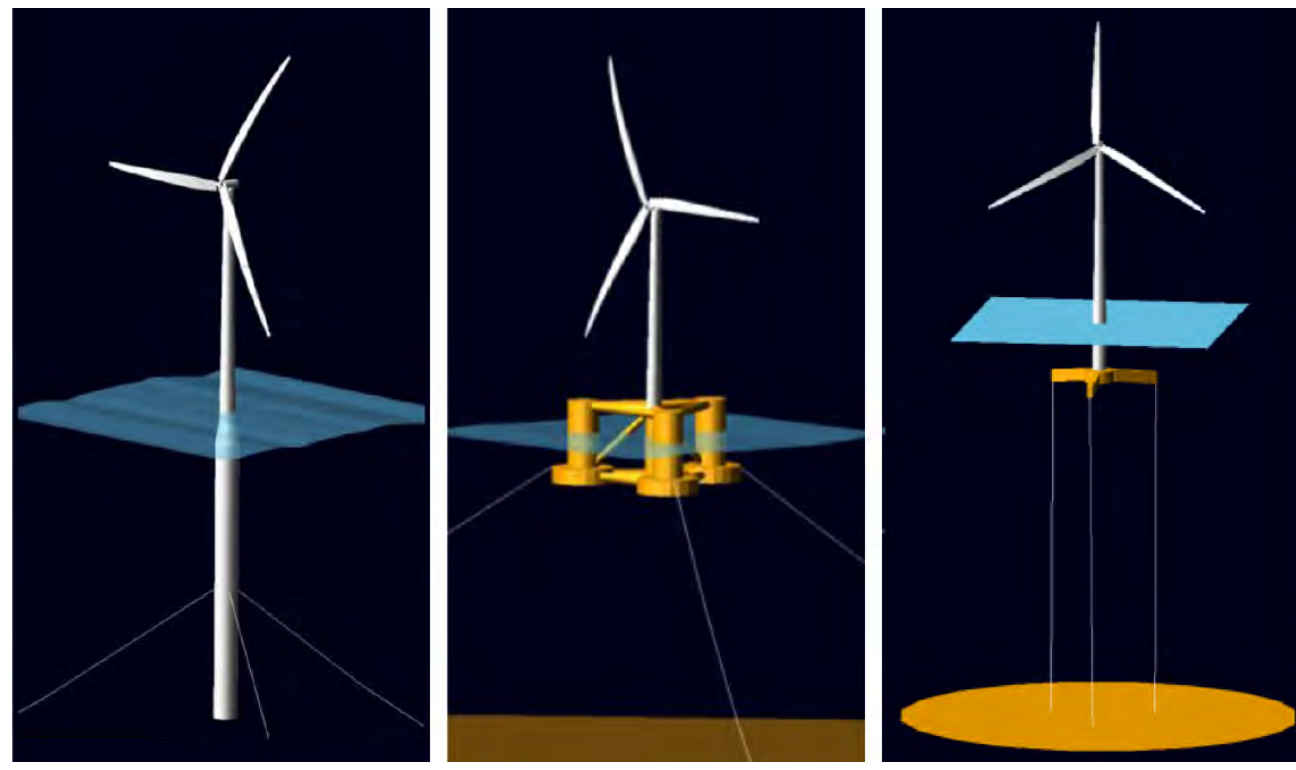

Figure 1. Sketch of the three platform concepts used in the study: UMaine Hywind spar (left), OC4 DeepCwind semisubmersible (center) and UMaine TLP (right) [16]

of the platform is $30 \mathrm{~m}$. The platform is relatively light and the excess of buoyancy is compensated by the mooring lines that are in tension and attached at the end of three $30 \mathrm{~m}$ length spokes that provide the restoring moment.

Table I collects the main parameters of the three platforms studied in this research.

Table I. Main parameters of the three platforms

\begin{tabular}{lccc}
\hline \hline & Spar & Semisubmersible & TLP \\
\hline Platform draft $(\mathrm{m})$ & 120 & 20 & 30 \\
Platform mass, including ballast (t) & 7,466 & 13,473 & 775 \\
CM location below SWL along platform centreline $(\mathrm{m})$ & 89.91 & 13.46 & 19.72 \\
Platform roll inertia about CM $\left(\mathrm{kgm}^{2}\right)$ & $4.23 \mathrm{E} 9$ & $6.827 \mathrm{E} 9$ & $1.5078 \mathrm{E} 8$ \\
Platform pitch inertia about CM $\left(\mathrm{kgm}^{2}\right)$ & $4.23 \mathrm{E} 9$ & $6.827 \mathrm{E} 9$ & $1.5078 \mathrm{E} 8$ \\
Platform yaw inertia about centreline $\left(\mathrm{kgm}^{2}\right)$ & $1.64 \mathrm{E} 8$ & $1.226 \mathrm{E} 10$ & $9.885 \mathrm{E} 7$ \\
Displaced water volume $\left(\mathrm{m}^{3}\right)$ & 8,035 & 13,917 & 2,767 \\
\hline
\end{tabular}

In the spar platform, a viscous drag coefficient of 0.6 is applied to the submerged portion of the platform cylinder introducing an additional damping in the direction perpendicular to the cylinder axis. Following the model description in [12], additional linear damping coefficient in the surge, sway, heave and yaw degrees of freedom was applied to capture accurately the platform dynamics. This additional damping is provided in Table II

Table II. Additional linear damping for the spar platform

\begin{tabular}{lc}
\hline \hline Surge & $100 \mathrm{kNs} / \mathrm{m}$ \\
Sway & $100 \mathrm{kNs} / \mathrm{m}$ \\
Heave & $130 \mathrm{kNs} / \mathrm{m}$ \\
Yaw & $13,000 \mathrm{kNms} / \mathrm{rad}$ \\
\hline
\end{tabular}


For the semisubmersible platform, a viscous drag coefficient was also applied in the cylindrical elements. The value of the coefficient, slightly different depending on the element diameter, is shown in Table III. For the viscous damping coefficient in the heave plates at the base of the columns, a value of 4.8 was used. In this case, the reference length for the computation of the viscous forces is the diameter of the plates.

Table III. Viscous drag damping coefficients in the semisubmersible platform elements

\begin{tabular}{ll}
\hline \hline Main column & 0.56 \\
Upper columns & 0.61 \\
Base columns & 0.68 \\
Pontoons and cross members & 0.63 \\
Heave plates & 4.80 \\
\hline
\end{tabular}

For the TLP, a viscous drag coefficient of 0.6 was defined for the three spokes and for the submerged portion of tower. In addition, the surface at the platform keel was considered as a heave plate with a drag coefficient of 4.8 and a effective radius of $7.5 \mathrm{~m}$.

In the three platforms considered, the mooring system of the platform is composed by three lines. The spar design has one downwind line aligned with the nominal wind direction (line 1) and two upwind lines forming a $60^{\circ}$ angle with the nominal wind direction (lines 2 and 3). For the semisubmersible and the TLP, the configuration is the opposite: one line is upwind and parallel to the nominal wind direction (line 2) and the other two are downwind forming a $60^{\circ}$ angle with the nominal wind direction (lines 1 and 3).

The characteristics of the mooring system of each platform are summarized in Table IV. A line-seabed contact model with no friction was included.

Parameters in Table IV are sufficient for the construction of a Quasi-Static mooring model, while for the dynamic mooring

Table IV. Main parameters of the three mooring systems

\begin{tabular}{lccc}
\hline \hline & Spar & Semisubmersible & TLP \\
\hline Number of mooring lines & 3 & 3 & 3 \\
Angle between adjacent lines & $120^{\circ}$ & $120^{\circ}$ & $120^{\circ}$ \\
Depth to anchors below SWL (m) & 200 & 200 & 200 \\
Depth to fairleads below SWL (m) & 70.0 & 14.0 & 28.5 \\
Radius to anchors from platform centreline (m) & 445 & 837.6 & 30.0 \\
Radius to fairleads from platform centreline (m) & 5.2 & 40.868 & 30.0 \\
Unstretched length (m) & 468 & 835.5 & 171.399 \\
Line diameter (m) & 0.09 & 0.0766 & 0.2216 \\
Equivalent mass density (kg/m) & 145 & 113.35 & 302.89 \\
Equivalent extensional stiffness (kN) & 384,243 & 753,600 & $7,720,000$ \\
\hline
\end{tabular}

model additional parameters presented in Table $\mathrm{V}$ are required. For the dynamic model, the added mass coefficient was set to 1 , according to [19]. A normal drag coefficient of 1.6 and no tangential drag based on the values provided by [20] were set for all lines. A seabed vertical stiffness and damping were defined for the dynamic line-seabed contact model. The number of elements of each line were selected after performing a sensitivity study running several simulations with double number of elements and with no significant changes appreciated in the results.

Finally, for the spar design has to be noted that the lines are attached to the platform using a delta connection to increase the mooring system stiffness in yaw. In the mooring model for the spar case implemented in this study, the delta connection was not modelled. Instead, the platform yaw stiffness of the platform was increased with $98340 \mathrm{kNm} / \mathrm{rad}$, as indicated in [12].

The wind turbine supported by the three platforms is the NREL offshore $5 \mathrm{MW}$ baseline, which is described in [15]. It is a 3-bladed upwind rotor with variable speed control and collective blade pitch angle. The controller used is described in [12]. The main parameters of the wind turbine are collected in Table VI. 
Table V. Additional parameters of the three mooring systems used in the dynamic model

\begin{tabular}{lccc}
\hline \hline & Spar & Semisubmersible & TLP \\
\hline Added mass coefficient & 1.0 & 1.0 & 1.0 \\
Normal drag coefficient & 1.6 & 1.6 & 1.6 \\
Tangential drag coefficient & 0.0 & 0.0 & 0.0 \\
Structural damping $(\%)$ & 1.0 & 1.0 & 1.0 \\
Seabed vertical stiffness $\left(\mathrm{N} / \mathrm{m}^{2}\right)$ & 500,000 & 500,000 & 500,000 \\
Seabed vertical damping $\left(\mathrm{Ns} / \mathrm{m}^{2}\right)$ & 30,000 & 30,000 & 30,000 \\
Number of elements of the line & 45 & 80 & 40 \\
\hline
\end{tabular}

Table VI. Main parameters of the NREL 5MW baseline wind turbine

\begin{tabular}{lc}
\hline \hline Nominal power & $5 \mathrm{MW}$ \\
Rotor diameter & $126 \mathrm{~m}$ \\
Hub height & $90 \mathrm{~m}$ \\
Cut-in, rated, cut-out wind speed & $3 \mathrm{~m} / \mathrm{s}, 11.4 \mathrm{~m} / \mathrm{s}, 25 \mathrm{~m} / \mathrm{s}$ \\
Cut-in, rated rotor speed & $6.9 \mathrm{rpm}, 12.1 \mathrm{rpm}$ \\
Rotor mass & $110,000 \mathrm{~kg}$ \\
Nacelle mass & $240,000 \mathrm{~kg}$ \\
Tower mass & $347,460 \mathrm{~kg}$ \\
\hline
\end{tabular}

\section{ENVIRONMENTAL CONDITIONS}

A location with a sea depth of approximately $200 \mathrm{~m}$ in the coast of Ireland was selected for the computation of the environmental conditions used in the study. The exact coordinates of this location are $52^{\circ} 10^{\prime} \mathrm{N}$ and $11^{\circ} 45^{\prime} \mathrm{W}$ (see Figure 2).

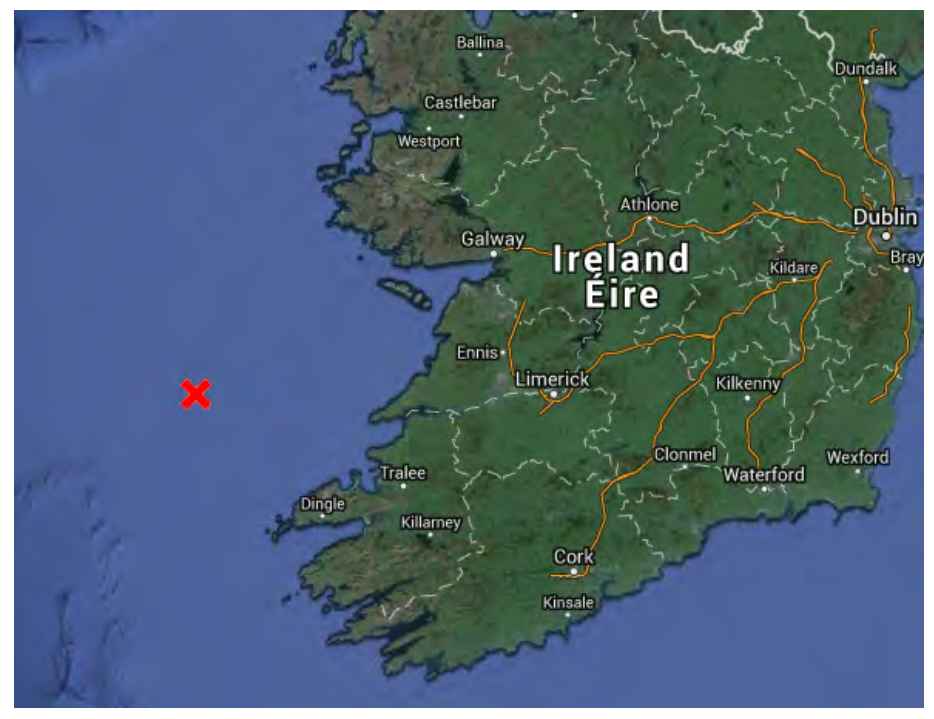

Figure 2. Theoretical location selected for the study (Source: Google Maps) 
An hourly wind and wave database between 2004 to 2011 was generated using the Skiron [21] and the WAM [22] models for the wind and the wave respectively. These data were used to generate the scatter tables that determine the significant wave height $\left(H_{s}\right)$ and reference peak spectral period $\left(T_{p}\right)$ as function of the wind speed $\left(V_{w}\right)$ required for the definition of each particular simulation load case according to the guideline. A Pierson-Moskowitz spectrum was assumed to represent the wave energy distribution. As the metoceanic model used did not include surface current data, a 1-year surface current velocity of $0.609 \mathrm{~m} / \mathrm{s}$ and a 50 -year surface current velocity of $1.31 \mathrm{~m} / \mathrm{s}$ were assumed. A summary of the environmental parameters is provided in Table VII.

Table VII. Summary of the location metoceanic data

\begin{tabular}{lc}
\hline \hline Sea depth & $200 \mathrm{~m}$ \\
1-year significant wave height & $9.82 \mathrm{~m}$ \\
1-year peak spectral period & $14.30 \mathrm{~s}$ \\
50-year significant wave height & $11.50 \mathrm{~m}$ \\
50-year peak spectral period & $15.48 \mathrm{~s}$ \\
\hline
\end{tabular}

\section{DESIGN LOAD CASES SIMULATED FOR THE FATIGUE AND ULTIMATE LOADS}

The computation of the fatigue and the ultimate loads followed the requirements of the IEC 61400-3 guideline [8]. This guideline defines a set of design load cases (DLC) covering all the significant conditions that an offshore wind turbine may experience. The guideline combines the wind turbine operational modes or design situations with external conditions including the control actions and the protection system. The load cases are divided into fatigue and ultimate cases.

The fatigue cases recreate different scenarios, such as power production, power production followed by grid loss, normal shut down and parked. Table VIII shows a description of the fatigue load cases simulated in our study. Cases of start-up, parked and fault and installation are usually considered with low impact on fatigue loads and, in consequence, were not included in the equivalent loads computation.

The Rainflow cycle counting method was applied to the fatigue load cases time series to obtain the number of cycles

Table VIII. Fatigue load cases definition

\begin{tabular}{|c|c|c|c|c|c|c|c|}
\hline Design Situation & DLC & $\begin{array}{c}\text { Wind } \\
\text { Condition }\end{array}$ & Waves & $\begin{array}{l}\text { Wind-Waves } \\
\text { directionality }\end{array}$ & $\begin{array}{c}\text { Sea } \\
\text { currents }\end{array}$ & Water level & Other \\
\hline Power Production & 1.2 & NTM & NSS & COD, MUL & No & $\begin{array}{l}\text { NWLR or } \\
\text { MSL }\end{array}$ & \\
\hline $\begin{array}{l}\text { Power production } \\
+ \text { fault }\end{array}$ & 2.4 & NTM & NSS & COD, UNI & No & $\begin{array}{l}\text { NWLR or } \\
\text { MSL }\end{array}$ & $\begin{array}{l}\text { Control, protection or } \\
\text { electrical faults }\end{array}$ \\
\hline Normal shut down & 4.1 & NWP & NSS & COD, UNI & No & $\begin{array}{l}\text { NWLR or } \\
\text { MSL }\end{array}$ & \\
\hline $\begin{array}{l}\text { Parked (standing } \\
\text { still/idling) }\end{array}$ & 6.4 & NTM & NSS & COD, MUL & No & $\begin{array}{l}\text { NWLR or } \\
\text { MSL }\end{array}$ & \\
\hline
\end{tabular}

COD: Co-Directional NSS: Normal Sea State NTM: Normal Turbulence Model NWLR: Normal Water Level Range NWP: Normal Wind Profile MSL: Mean Sea Level MUL: Multi-Directional UNI: Uni-Directional

and range. For the calculation of the fatigue equivalent loads, the cycles of each load case are weighted according to the relative importance of the case in the turbine lifetime. The fatigue equivalent loads in this study were calculated based on $1 \mathrm{E} 7$ cycles in 20 years of lifetime using the following expression:

$$
F_{\text {equivalent }}=\left(\frac{\sum_{i} n_{i} S_{i}^{m}}{T f}\right)^{\frac{1}{m}}
$$


where $n_{i}$ is the number of cycles in load range, $S_{i}, T$ is the duration of the original time history, $f$ is the frequency of the equivalent load and $m$ is the inverse $\mathrm{S}-\mathrm{N}$ material slope.

The ultimate load cases recreate extreme scenarios as emergency shutdowns, parked and fault conditions and extreme environmental conditions. A brief description of the load cases for the calculation of the the ultimate loads can be found in Table IX. A detailed definition can be found in the guideline [8]. All the load cases requested by the guideline were computed, with the exception of the case group 8 and a certain number of subcases of the 2.2 group. The case group 8 simulates transport, assembly, maintenance and repair and are usually considered benign. The subcases of the 2.2 group discarded, simulate a fault in the nacelle yaw angle control, provoking a yaw rotation of the nacelle (yaw runaway) of $360^{\circ}$. In these cases, when the yaw angle of the nacelle reaches $180^{\circ}$, the wind attacks the rotor from a direction opposite to the design condition, and the behaviour of the wind turbine is very sensitive to the control design. The controller implemented in our different wind turbines is a baseline controller that does not take into account such specific conditions, consequently not being representative of the real conditions. The corresponding safety factor was applied to the loads of different cases, according to the standard specifications.

More than 3.500 load cases were simulated for each platform concept and for each mooring system modelling approach (around 400 fatigue load cases and 3.100 extreme load cases). In total more than 20,000 load cases were computed for this study. The cases were launched in the cluster with 40 nodes, 400 cores and $500 \mathrm{~Gb}$ of RAM, taking around 5 days the simulation of the whole set of cases. The FAST and OPASS output files were converted to BLADED binary format and BLADED postprocessing tools were used for the computation of the fatigue and ultimate loads. The amount of data postprocessed for each platform and mooring approach case was around $200 \mathrm{~GB}$.

Figure 3 shows the reference system for the loads at the different wind turbine components: blade, low speed shaft (LSS) and tower.
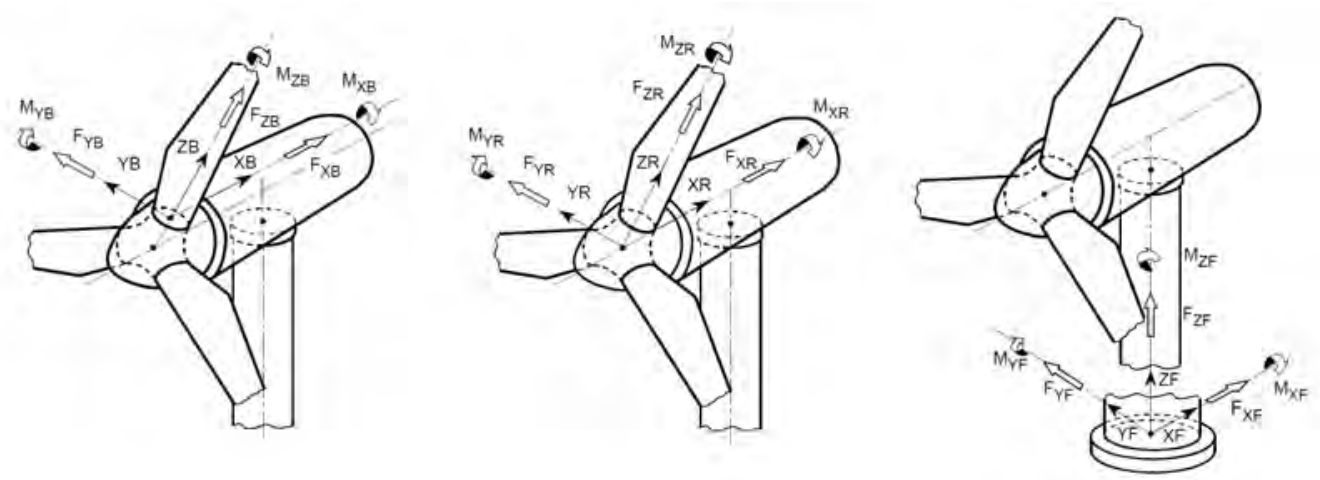

Figure 3. Reference system for the loads at the different wind turbine components: blade root (left), rotating low speed shaft (center) and tower base (right). Source: GL [23]

The three forces and moments $\left(F_{x}, F_{y}, F_{z}, M_{x}, M_{y}\right.$ and $\left.M_{z}\right)$ were computed at the blade root, the low speed shaft and the tower base of the wind turbine. In addition, the tension at the anchor and fairlead of each mooring line were also computed. The equivalent fatigue loads for the steel elements (moorings, tower and shaft) are based on a S-N slope of 4, while a slope of 9 was used for the blade. The blade root ultimate loads were calculated based on the extreme loads found at any of the three blades.

In the following sections the results for the fatigue loads (Section 7 ) and for the ultimate loads (Section 8 ) are discussed. For the sake of brevity, only the three moments at each component are presented in these sections, skipping the forces whose behaviour is similar to the corresponding moment. The tension of the mooring lines is presented only at the anchor, having the tension at the fairleads a similar behaviour. 
Table IX. Ultimate load cases definition

\begin{tabular}{|c|c|c|c|c|c|c|c|}
\hline Design Situation & DLC & $\begin{array}{c}\text { Wind } \\
\text { Condition }\end{array}$ & Waves & $\begin{array}{l}\text { Wind-Waves } \\
\text { directionality }\end{array}$ & $\begin{array}{c}\text { Sea } \\
\text { currents }\end{array}$ & Water level & Other \\
\hline \multirow{6}{*}{$\begin{array}{l}\text { Power } \\
\text { Production }\end{array}$} & 1.1 & NTM & NSS & $\mathrm{COD}, \mathrm{UNI}$ & $\mathrm{NCM}$ & MSL & \\
\hline & 1.3 & ETM & NSS & $\mathrm{COD}, \mathrm{UNI}$ & $\mathrm{NCM}$ & MSL & \\
\hline & 1.4 & ECD & $\begin{array}{l}\text { NSS or } \\
\text { NWH }\end{array}$ & $\begin{array}{l}\text { MIS, wind direction } \\
\text { change }\end{array}$ & $\mathrm{NCM}$ & MSL & \\
\hline & 1.5 & EWS & NSS & $\mathrm{COD}, \mathrm{UNI}$ & $\mathrm{NCM}$ & MSL & \\
\hline & $1.6 \mathrm{a}$ & NTM & SSS & $\mathrm{COD}, \mathrm{UNI}$ & $\mathrm{NCM}$ & NWLR & \\
\hline & $1.6 \mathrm{~b}$ & NTM & SWH & $\mathrm{COD}, \mathrm{UNI}$ & $\mathrm{NCM}$ & NWLR & \\
\hline \multirow{3}{*}{$\begin{array}{l}\text { Power } \\
\text { production + } \\
\text { fault }\end{array}$} & 2.1 & NTM & NSS & $\mathrm{COD}, \mathrm{UNI}$ & $\mathrm{NCM}$ & MSL & $\begin{array}{l}\text { Control fault or loss of } \\
\text { network }\end{array}$ \\
\hline & 2.2 & NTM & NSS & $\mathrm{COD}, \mathrm{UNI}$ & $\mathrm{NCM}$ & MSL & $\begin{array}{l}\text { Protection system or internal } \\
\text { electrical fault }\end{array}$ \\
\hline & 2.3 & EOG & $\begin{array}{l}\text { NSS or } \\
\text { NWH }\end{array}$ & $\mathrm{COD}, \mathrm{UNI}$ & $\mathrm{NCM}$ & MSL & $\begin{array}{l}\text { Electrical fault, loss of net- } \\
\text { work }\end{array}$ \\
\hline $\begin{array}{l}\text { Normal shut } \\
\text { down }\end{array}$ & 4.2 & EOG & $\begin{array}{l}\text { NSS or } \\
\text { NWH }\end{array}$ & $\mathrm{COD}, \mathrm{UNI}$ & $\mathrm{NCM}$ & MSL & \\
\hline $\begin{array}{l}\text { Emergency shut } \\
\text { down }\end{array}$ & 5.1 & NTM & $\begin{array}{l}\text { NSS or } \\
\text { NWH }\end{array}$ & $\mathrm{COD}, \mathrm{UNI}$ & $\mathrm{NCM}$ & MSL & \\
\hline \multirow{7}{*}{$\begin{array}{l}\text { Parked (standing } \\
\text { still/idling) }\end{array}$} & $6.1 \mathrm{a}$ & $\begin{array}{c}\text { EWM } \\
\text { (Turbulent) }\end{array}$ & ESS & MIS, MUL & ECM & EWLR & \\
\hline & $6.1 \mathrm{~b}$ & $\begin{array}{l}\text { EWM } \\
\text { (Steady) }\end{array}$ & RWH & MIS, MUL & ECM & EWLR & \\
\hline & $6.1 \mathrm{c}$ & $\begin{array}{l}\text { RWM } \\
\text { (Steady) }\end{array}$ & EWH & MIS, MUL & ECM & EWLR & \\
\hline & $6.2 \mathrm{a}$ & $\begin{array}{c}\text { EWM } \\
\text { (Turbulent) }\end{array}$ & ESS & MIS, MUL & ECM & EWLR & Loss of network \\
\hline & $6.2 b$ & $\begin{array}{l}\text { EWM } \\
\text { (Steady) }\end{array}$ & RWH & MIS, MUL & ECM & EWLR & Loss of network \\
\hline & $6.3 \mathrm{a}$ & $\begin{array}{c}\text { EWM } \\
\text { (Turbulent) }\end{array}$ & ESS & MIS, MUL & ECM & EWLR & Extreme yaw misalignement \\
\hline & $6.3 \mathrm{~b}$ & $\begin{array}{l}\text { EWM } \\
\text { (Steady) }\end{array}$ & RWH & MIS, MUL & ECM & EWLR & Extreme yaw misalignement \\
\hline \multirow{3}{*}{ Parked + fault } & $7.1 \mathrm{a}$ & $\begin{array}{c}\text { EWM } \\
\text { (Turbulent) }\end{array}$ & ESS & MIS, MUL & ECM & EWLR & \\
\hline & $7.1 \mathrm{a}$ & $\begin{array}{l}\text { EWM } \\
\text { (Steady) }\end{array}$ & RWH & MIS, MUL & ECM & EWLR & \\
\hline & 7.1a & $\begin{array}{l}\text { RWM } \\
\text { (Steady) }\end{array}$ & EWH & MIS, MUL & ECM & EWLR & \\
\hline
\end{tabular}

COD: Co-Directional ECD: Extreme Coherent gust with Direction change ECM: Extreme Current Model EOG: Extreme Operating Gust ESS: Extreme Sea State ETM: Extreme Turbulent Model EWH: Extreme Wave Height EWLR: Extreme Water Level Range EWM: Extreme Wind Model EWS: Extreme Wind Shear MIS: Misaligned MSL: Mean Sea Level MUL: Multi-Directional NCM: Normal Current Model NSS: Normal Sea State NTM: Normal Turbulence Model NWH: Normal Wave Height NWLR: Normal Water Level Range RWH: Reduced Wave Height RWM: Reduced Wind speed Model SSS: Severe Sea State SWH: Severe Wave Height UNI: Uni-Directional 


\section{IMPACT OF MOORING LINES DYNAMICS ON FATIGUE LOADS}

\subsection{UMaine Hywind spar fatigue loads}

The pitch and roll motions have a great impact on the level of loads of the wind turbine components. The simulations using the Quasi-Static and the dynamic moorings models provide very similar pitch and roll motions for the spar concept because the fairleads are located very close to the center of rotation of the system. The fatigue analysis reveals no significant differences (below 1\%) in the equivalent loads obtained with the two mooring models for the wind turbine components (blades, shaft and tower), see Figure 4, Figure 5 and Figure 6.

On the other hand, the additional drag introduced by the dynamic model of the lines slightly reduces the translational surge and sway motions of the platform in comparison with the Quasi-Static model. Though this implies opposite effects on the tension of the lines (the drag would increase the line tension for a prescribed movement, but the additional damping reduces the motions of the line fairlead decreasing the peaks of tension), the combined effect results in a reduction on the tension peaks. Figure 7 shows significant differences for the fatigue equivalent tension of the moorings computed with the Quasi-Static and the dynamic models. The Quasi-Static model provides up to $8 \%$ higher tensions than the dynamic.

As the environmental conditions of the fatigue cases are moderate, the accelerations of the platform are not high and the inertial effect of the lines does not have an important impact on the computation of the spar fatigue loads.

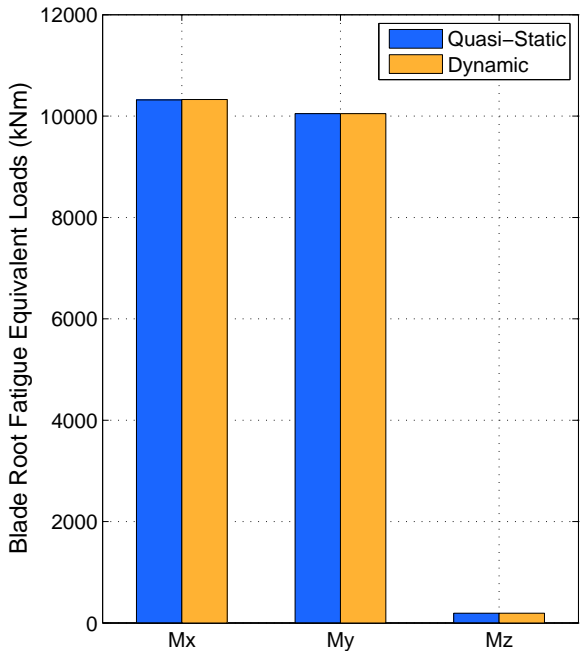

Figure 4. Spar combined blade root fatigue equivalent loads

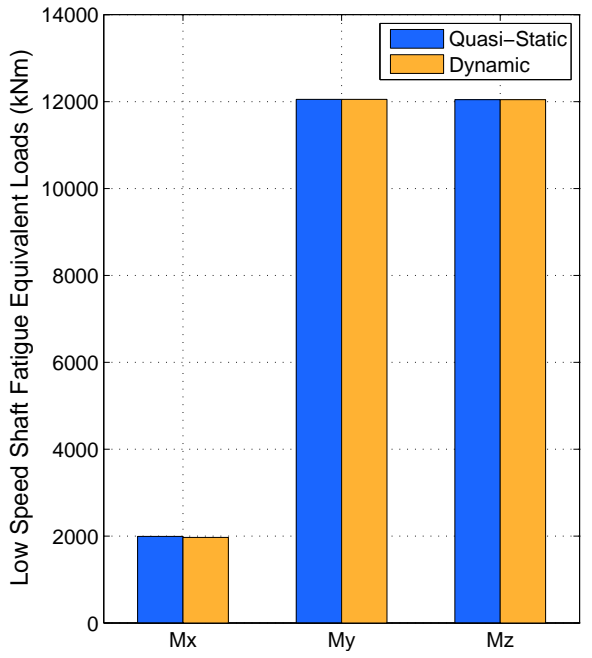

Figure 5. Spar low speed shaft fatigue equivalent loads 


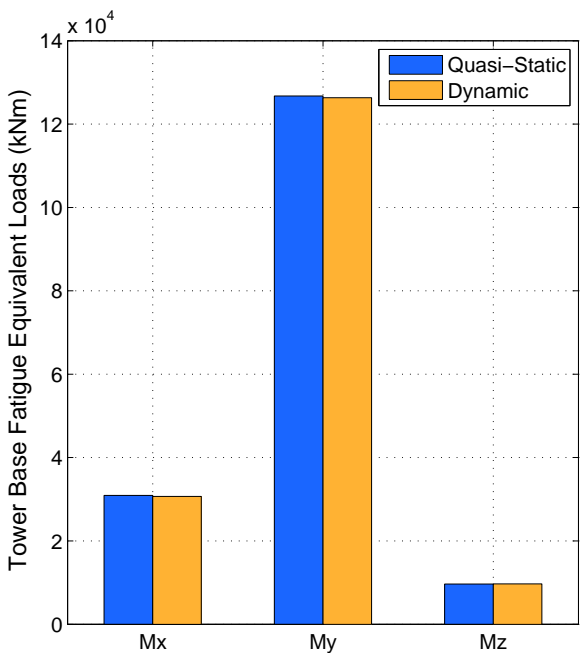

Figure 6. Spar tower base fatigue equivalent loads

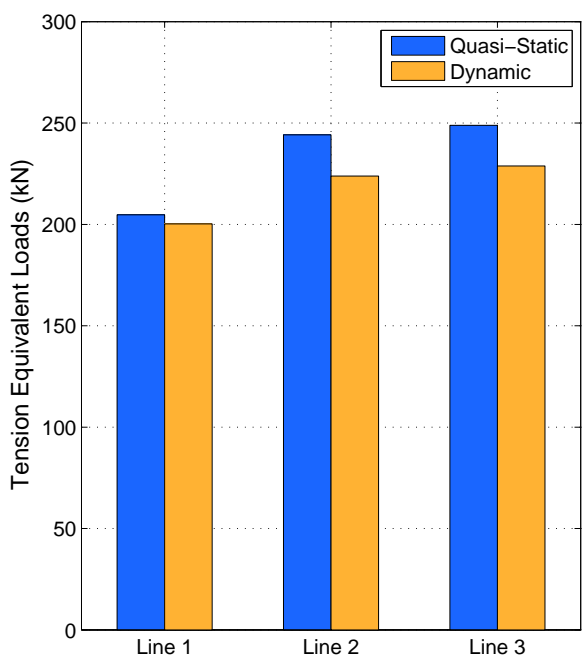

Figure 7. Spar moorings equivalent tension at anchor

\subsection{OC4 DeepCwind semisubmersible fatigue loads}

In contrast with the spar concept, in the semisubmersible model the lines are attached at a considerable radius from the platform center, providing an important restoring arm for the pitch and roll rotations. In consequence, the additional damping of the dynamic model decreases the amplitude of the platform rotations. The effect over the blades and the shaft fatigue loads is minimal (see Figure 8 and Figure 9 ). The differences in the platform rotations have a significant impact on the tower base moment, see Figure 10, due to important tower height and high gravity and inertial forces generated by the tower top mass. The dynamic model introduces reductions of $13 \%$ in the tower base $M_{x}$ component and $2 \%$ in the $M_{y}$ component.

The effect of the mooring dynamics is very relevant for the fatigue of the lines. Figure 11 shows how the dynamic model increases the tension equivalent load in $26 \%$ and $30 \%$ for the downwind lines 1 and 3, respectively and 57\% for the upwind line 2, in comparison with the values provided when the Quasi-Static model is used.

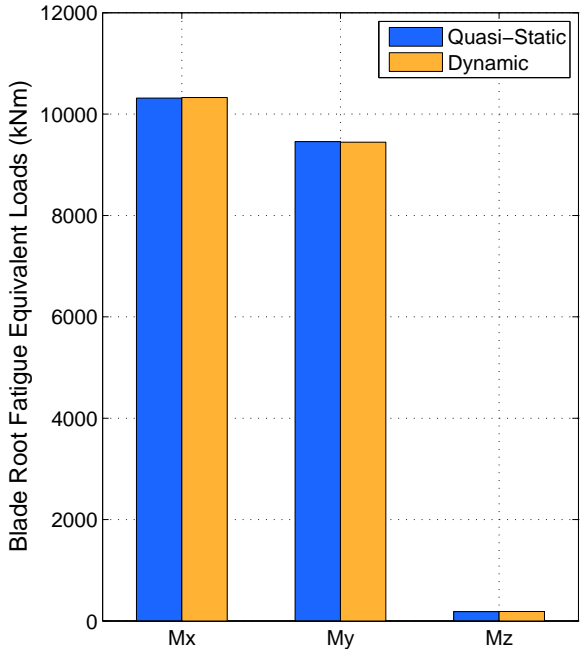

Figure 8. Semisubmersible combined blade root fatigue equivalent loads

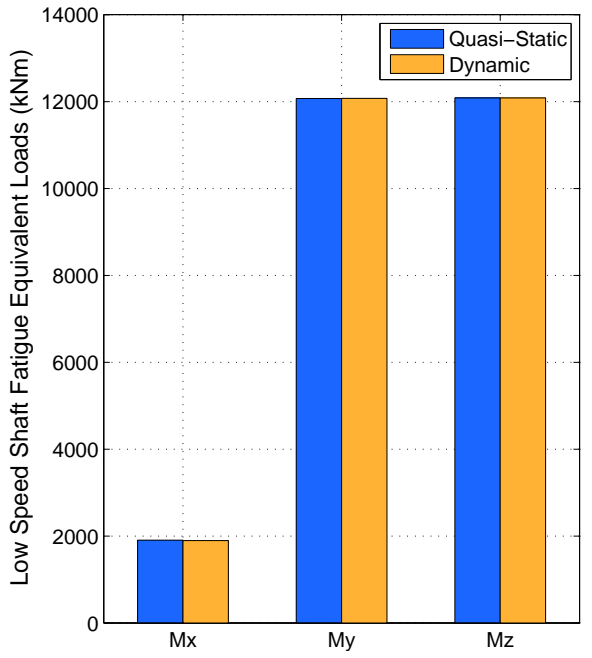

Figure 9. Semisubmersible low speed shaft fatigue equivalent loads 


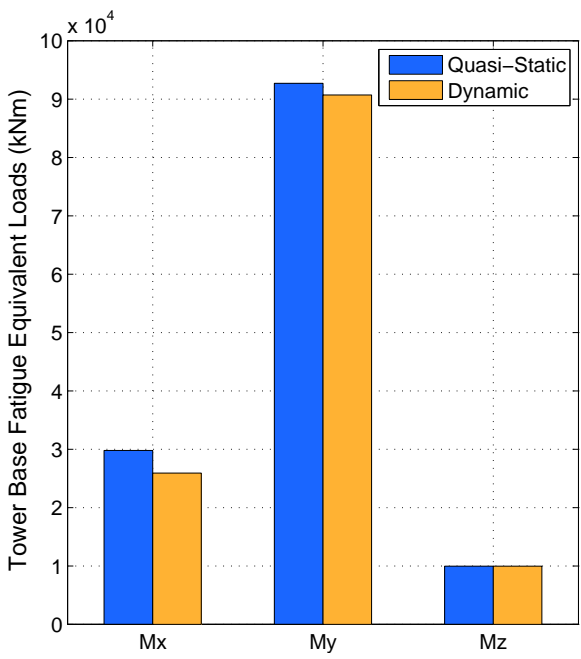

Figure 10. Semisubmersible tower base fatigue equivalent loads

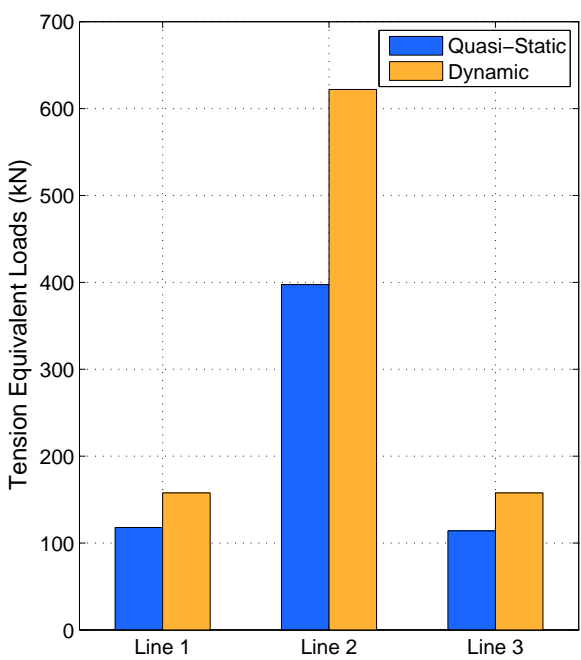

Figure 11. Semisubmersible moorings equivalent tension at the anchors

The great impact of the mooring dynamics on the fatigue of the lines is caused by the presence of the semisubmersible heave natural period $(17.5 \mathrm{~s})$ inside the wave spectrum. We have verified that the cases with $T_{p}=17.5 \mathrm{~s}$ provide $60 \%$ of the total fatigue load when the dynamic mooring model is used, and only $9.6 \%$ if it is the Quasi-Static. When a natural period of the platform is inside the wave spectrum, the guideline requires the simulation of cases with the same wave peak period as the platform natural period. In the UMaine Hywind spar these cases with $T_{p}=17.5 \mathrm{~s}$ produce a great excitation of the platform motion, activating the inertial effects of the lines and increasing the tensions for the dynamic model. We have verified that the cases with $T_{p}=17.5 \mathrm{~s}$ are the ones with the highest contribution to the tension equivalent fatigue loads.

Figure 12 presents the Power Spectrum Density (PSD) of the platform heave displacement for 4 power production fatigue load cases computed with the OPASS dynamic mooring model. Each of these cases has different wave spectrum peak period $(7.05 \mathrm{~s}, 10.53 \mathrm{~s}, 13.29 \mathrm{~s}$ and $17.50 \mathrm{~s})$ and the same turbulent wind of $12.1 \mathrm{~m} / \mathrm{s}$ mean speed. The PSD shows that the platform heave motion increases as the peak frequency approaches to the heave natural frequency, becoming very important for the case with $T_{p}=17.50 \mathrm{~s}$. Figure 13 shows the PSD of the platform line 2 (upwind) tension for the same 4 cases. A peak at the platform surge natural frequency $(0.009 \mathrm{~Hz})$ is present in all the simulations, but the highest peak appears for $T_{p}=17.50 \mathrm{~s}(0.057 \mathrm{~Hz})$, showing that the platform heave excitation plays an important role on the fatigue of the lines. 


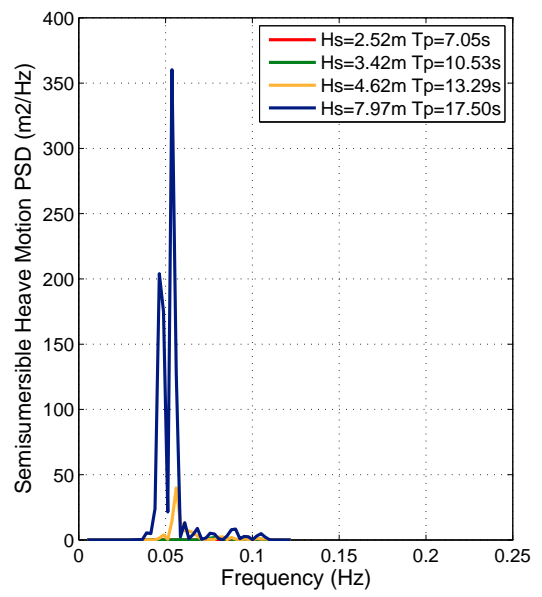

Figure 12. PSD of the semisubmersible heave displacement with different $T_{p}$ using dynamic mooring model

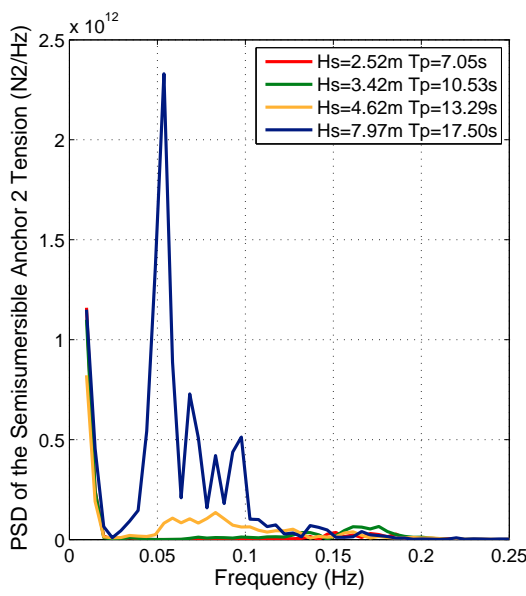

Figure 13. PSD of the semisubmersible line 2 tension with different $T_{p}$ using dynamic mooring model

Figure 14 shows, for a case with $T_{p}=17.50 \mathrm{~s}$, that the amplitude of the heave displacement is slightly lower due to the effect of damping when the dynamic model is used if compared to the Quasi-Static, where the damping is absent. Figure 15 shows how the inertial effects captured by the dynamic model produce an important increase on the tension peaks.

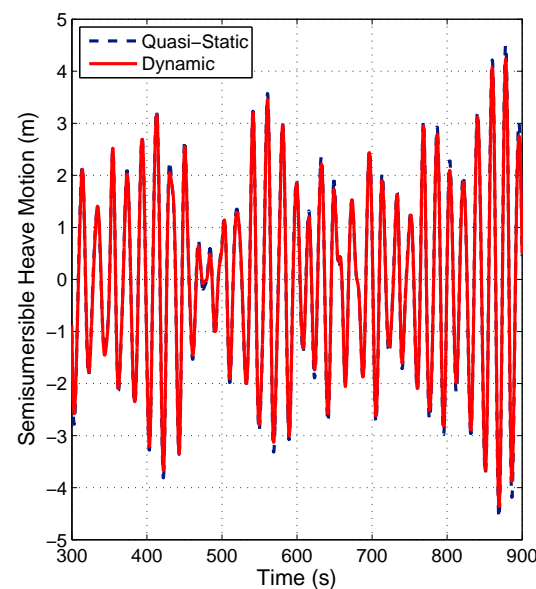

Figure 14. Heave displacement computed with dynamic and Quasi-Static models in a case with $H_{s}$ $=7.97 \mathrm{~m}, T_{p}=17.5 \mathrm{~s}$ and $V_{w}=12.1 \mathrm{~m} / \mathrm{s}$

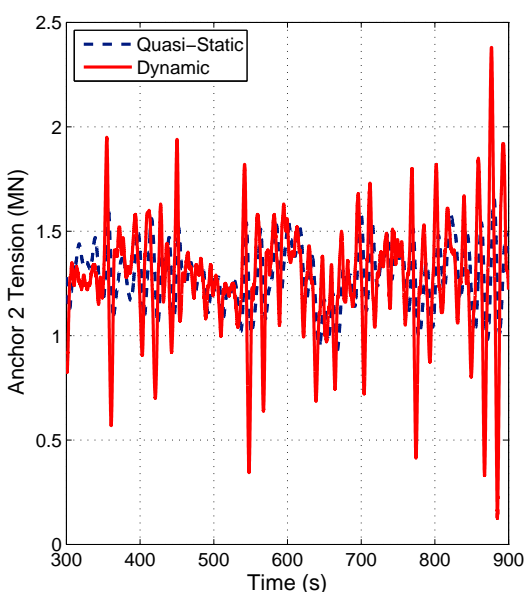

Figure 15. Fairlead 2 tension computed with dynamic and Quasi-Static models in a case with $H_{s}$ $=7.97 \mathrm{~m}, T_{p}=17.5 \mathrm{~s}$ and $V_{w}=12.1 \mathrm{~m} / \mathrm{s}$

\subsection{UMaine TLP fatigue loads}

The motions of the TLP platform, both translations and rotations, are more damped in the cases simulated with the dynamic moorings model that includes the drag on the lines than in those using the Quasi-Static model, where this effect is absent.

Nevertheless, Figure 16 and Figure 17 show that there are no significant differences on the fatigue loads of the blade root and the shaft obtained with the Quasi-Static and the dynamic mooring models. The reduced rotations of the platform obtained with the dynamic model are reflected in a reduction of the tower base loads, see Figure 18. This decrease is around $30 \%$ for the $M_{x}$ component of the tower base moment and only $2.5 \%$ for the $M_{y}$ component, where the effect of the lines damping is hidden by the aerodynamic loading at the rotor.

The fatigue equivalent tensions obtained with the dynamic model are lower in comparison with the Quasi-Static approach 
for the three lines, as Figure 19 shows. The differences are of $2 \%$ for the line 2 (upwind), and $4.5 \%$ and $4 \%$ for lines 1 and 3 (downwind). Again, the damping captured the dynamic model reduces the platform motions resulting in a decrease of the amplitude of the tension peaks.

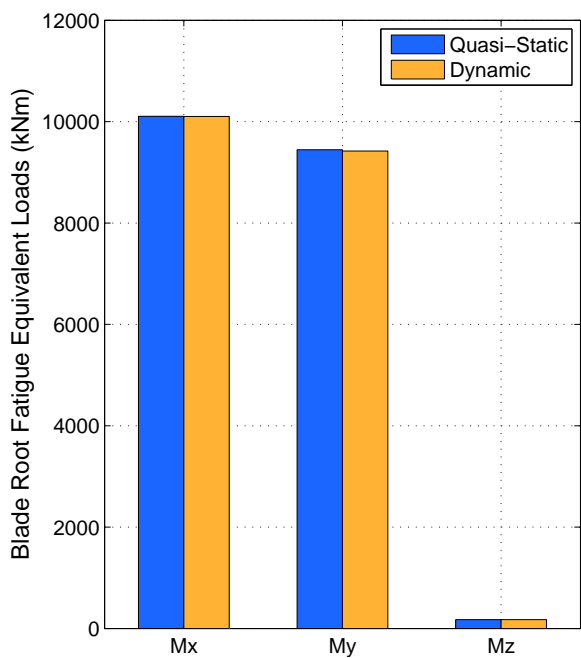

Figure 16. TLP combined blade root fatigue equivalent loads

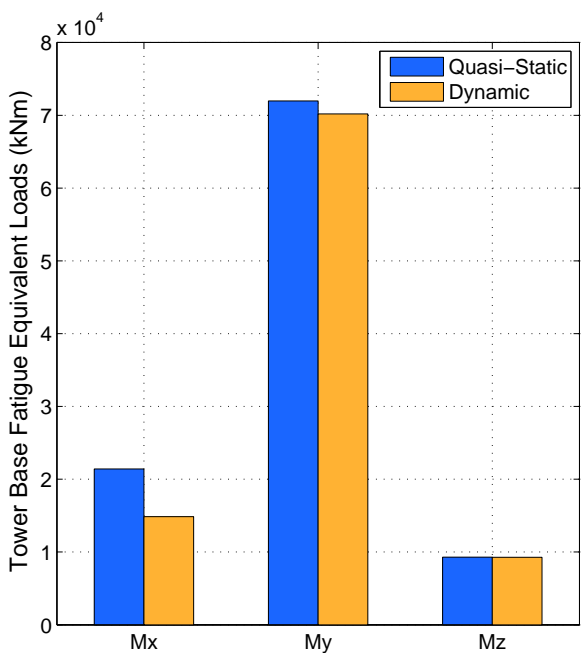

Figure 18. TLP tower base fatigue equivalent loads

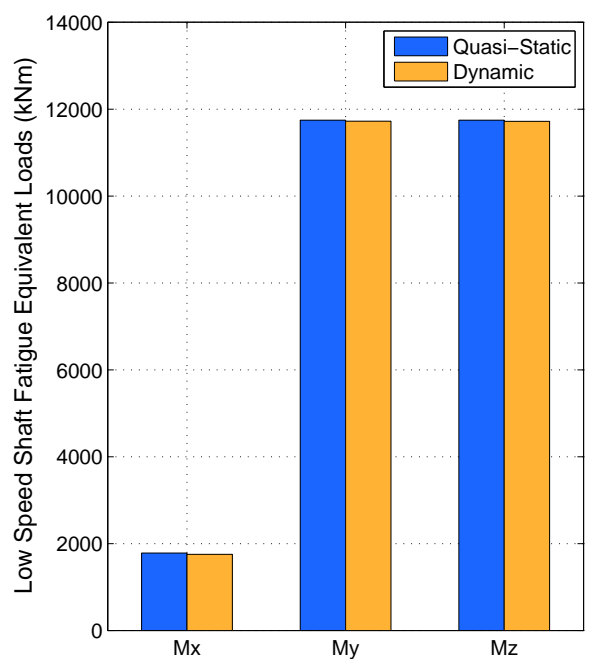

Figure 17. TLP low speed shaft fatigue equivalent loads

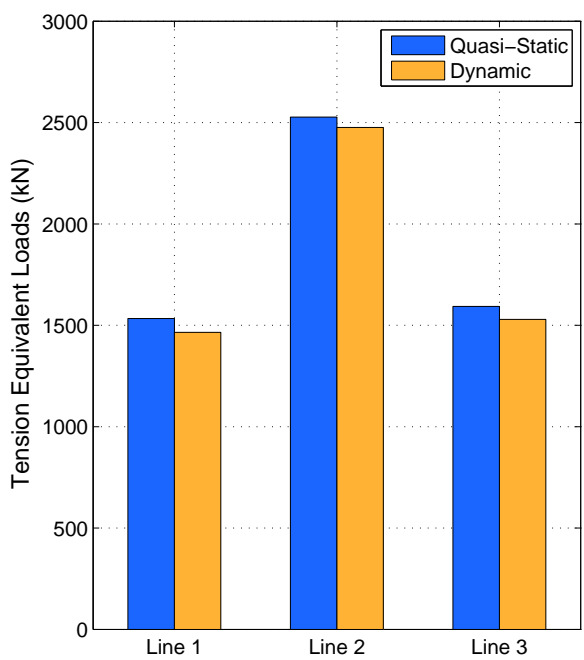

Figure 19. TLP moorings equivalent tension at the anchors

\subsection{Summary of the effect of mooring lines dynamics on the fatigue loads of the three platforms}

In this Subsection, the relative differences between the loads computed using the Quasi-Static and the dynamic moorings model are compared for the three platforms to identify in which components and platform designs the effect of the lines dynamics is more important. A positive value in the differences means higher loads calculated using dynamic lines model and a negative value means lower loads calculated by the dynamic model in comparison with the Quasi-Static.

Figure 20 and Figure 21 show that the effect of the lines dynamics only slightly affect the equivalent fatigue loads at the blade root and the low speed shaft for any of the three platforms, with differences below $0.3 \%$ in the blade root and $2 \%$ in 
the shaft. Nevertheless, small differences in fatigue loads of an element can have an impact on the design.

The mooring lines dynamic model produces a decrease in the tower fatigue loads (Figure 22) for the three platform designs. This decrease is higher for the component $M_{x}$ of the tower base moment, in particular for the TLP platform (31\%), being also important for the semisubmersible (13\%). The decrease in the $M_{y}$ component is lower due to the effect of the rotor aerodynamic thrust: around $2 \%$ and $2.5 \%$ for the semisubmersible and the TLP, respectively. For the spar, the reduction in the tower base moment is very small due to the reduced influence of the mooring system on the platform rotations.

Figure 23 shows that the effect of dynamics is very important on the line tension, reducing the fatigue loads for the spar and the TLP due to the extra damping that is not captured by the Quasi-Static approach. For the spar, the decrease is around $8 \%$ for the lines 2 and 3, that are oriented upwind and $2 \%$ for the downwind line. For the TLP the mooring approach is not so critical: using the dynamic model decreases less than $5 \%$ the equivalent tension in the upwind lines and around $2 \%$ in the downwind line. For the semisubmersible platform, where the heave natural frequency is inside the wave spectrum, the effect of the mooring dynamics is different than in the other two platforms. The excitation of the platform's heave displacement produces high velocities and accelerations in the lines increasing the loads due to the drag and inertia. In this case, the dynamic model provides $57 \%$ higher equivalent tension loads for the upwind line (line 2) with respect to the Quasi-Static, and between 25\% - 30\% for the downwind lines (lines 1 and 3).

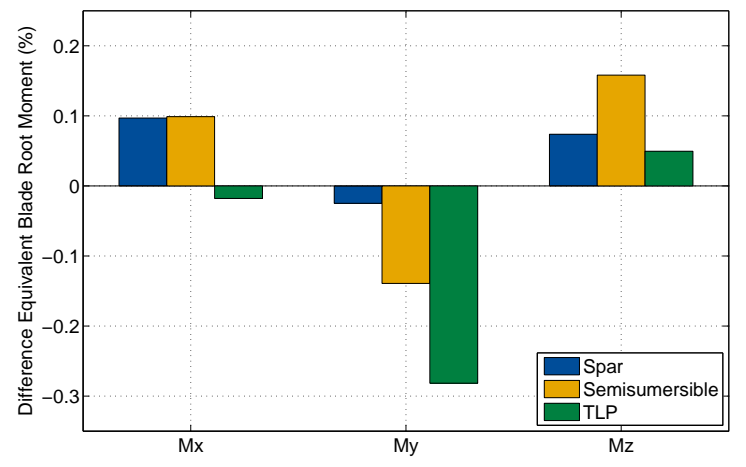

Figure 20. Differences in the blade fatigue loads computed with moorings dynamics compared with Quasi-Static

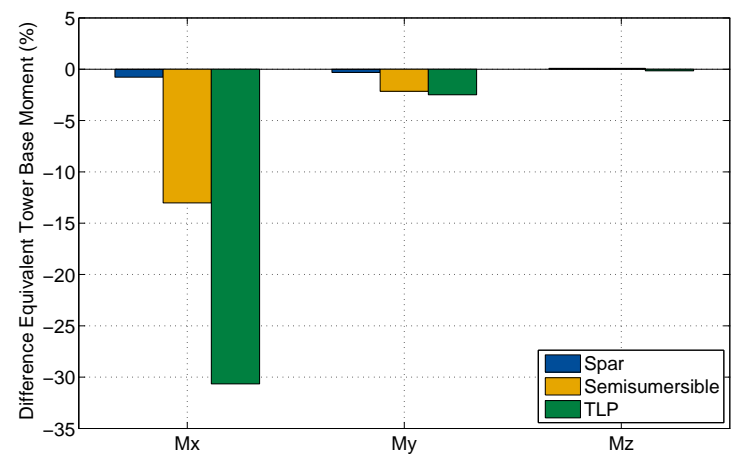

Figure 22. Differences in the tower base fatigue loads computed with moorings dynamics compared with Quasi-Static

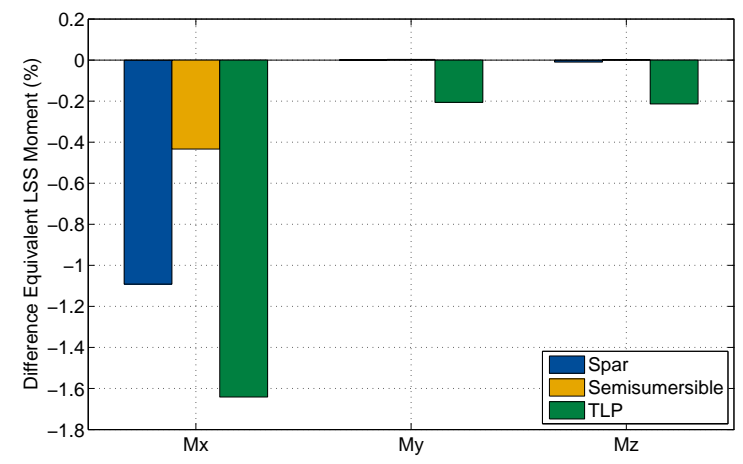

Figure 21. Differences in the shaft fatigue loads computed with moorings dynamics compared with Quasi-Static

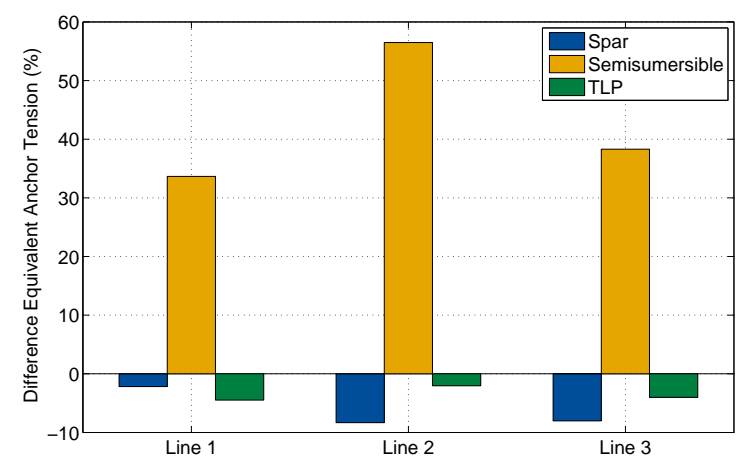

Figure 23. Differences in the lines anchor fatigue equivalent tension computed with moorings dynamics compared with Quasi-Static

\subsection{Importance of the DLC's groups on the fatigue equivalent loads}

Finally, to end with the fatigue analysis, the relative importance of each case group in the total fatigue equivalent loads were computed and is briefly presented in this Subsection.

DLC 1.2 is the most important group of cases and provides around $99 \%$ of the fatigue for almost all the wind turbine component loads in the three platforms considered in this study. The only exception is the tower base load in the TLP, 
where DLC 6.4 contributed with 3-5\% of the load. The importance of DLC 2.4 and DLC 4.1 is neglectable.

For the equivalent fatigue tension of the lines, DLC 2.4 and DLC 4.1 are also neglectable, but the role of DLC 6.4 is higher than in the wind turbine components, specially when dynamic mooring model is used. For the spar, DLC 6.4 provides $6 \%$ of the fatigue load in the downwind line with the dynamic model, but less than $1 \%$ with the Quasi-Static. For the semisubmersible, if the dynamic model is used, DLC 6.4 contributes with $14 \%$ of the fatigue load in the two downwind lines and around 7\% in the upwind line. But if the Quasi-Static model is used, the contribution of DLC 6.4 is reduced to $3 \%$ for the downwind lines and below $1 \%$ for the upwind. Finally, for the TLP, the relative importance of the DLC's in the fatigue calculation is similar for both mooring models; DLC 6.4 contributes with 6-7\% of the total fatigue damage in the downwind lines and 3.6\% in the upwind line, no matter which model is used. The rest of the fatigue load is provided by DLC 1.2.

\section{IMPACT OF MOORING LINES DYNAMICS ON ULTIMATE LOADS}

In this Section, the ultimate loads are provided in bar diagrams, and at the top of each bar, the load case group providing each ultimate load is indicated for information. A discussion on the importance of the different load case groups are provided at the end of the Section.

\subsection{UMaine Hywind spar ultimate loads}

The effect of the mooring line dynamics on the ultimate loads of the wind turbine components is very low for the spar, as can be seen in Figure 24 (blade root), Figure 25 (shaft) and Figure 26 (tower base). The differences on the modelling of the lines does not affect the platform motions in roll and pitch due to the position of the fairleads close to the platform rotation center.

The lines extreme tensions are sensitive to the lines model, as it is appreciated in Figure 27. The extreme environmental conditions defined for the simulation of the ultimate loads cases induce higher velocities and accelerations to the platform than in the fatigue cases. This leads to higher loads in the lines when the dynamic model is used, due to the drag and the inertial effects. The maximum tension of the lines is increased by $11 \%$ for line 1 and by $15 \%$ for the lines 2 and 3 . The minimum tensions are also decreased by the dynamic model.

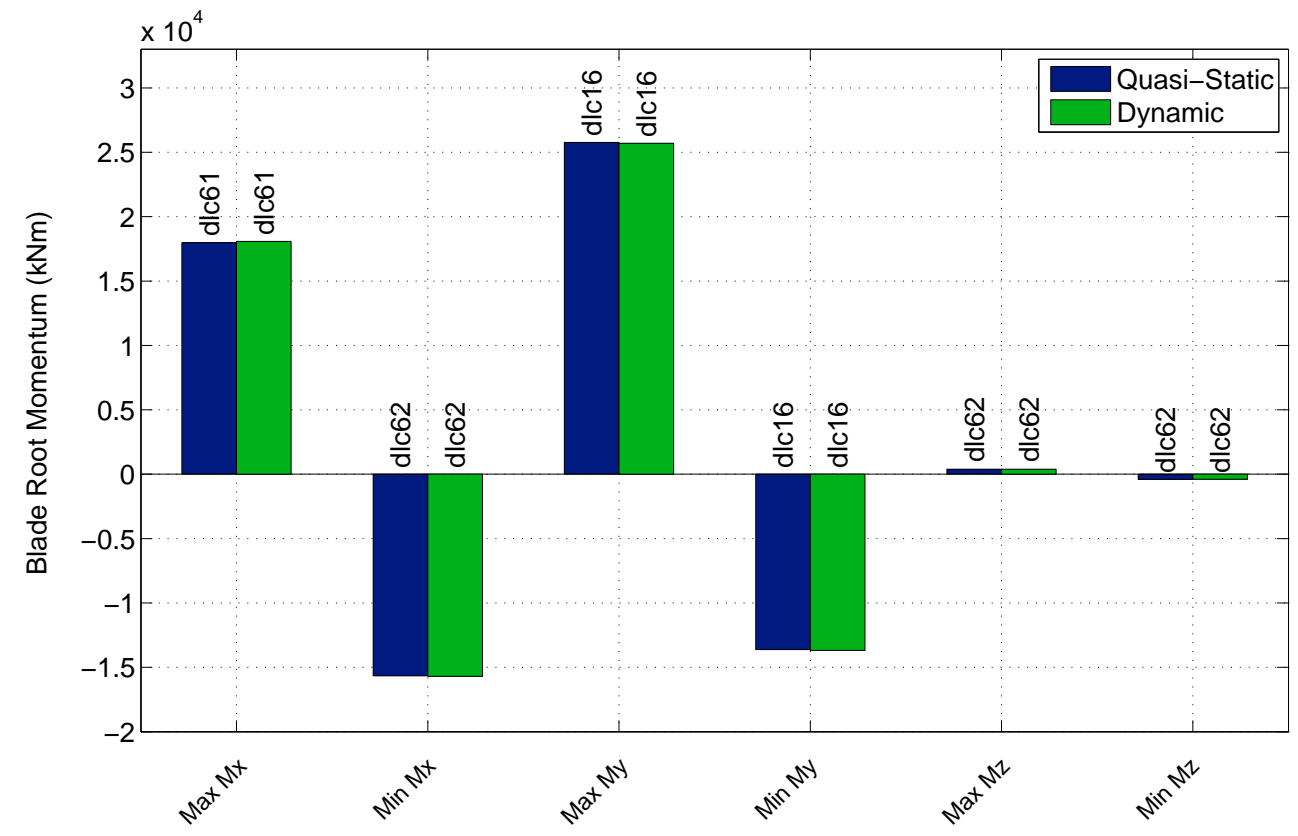

Figure 24. Ultimate loads at blade root for the spar platform 


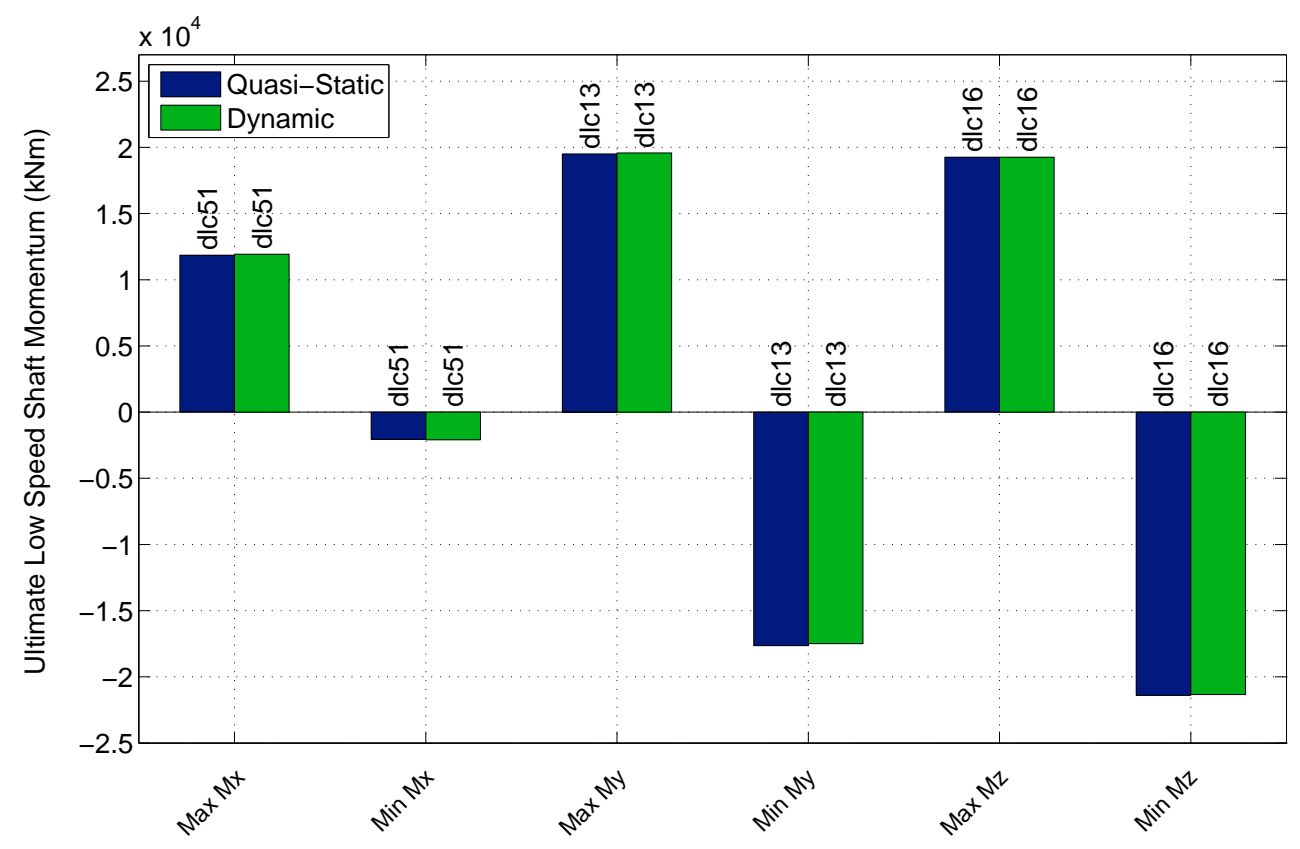

Figure 25. Ultimate loads at the low speed shaft for the spar platform

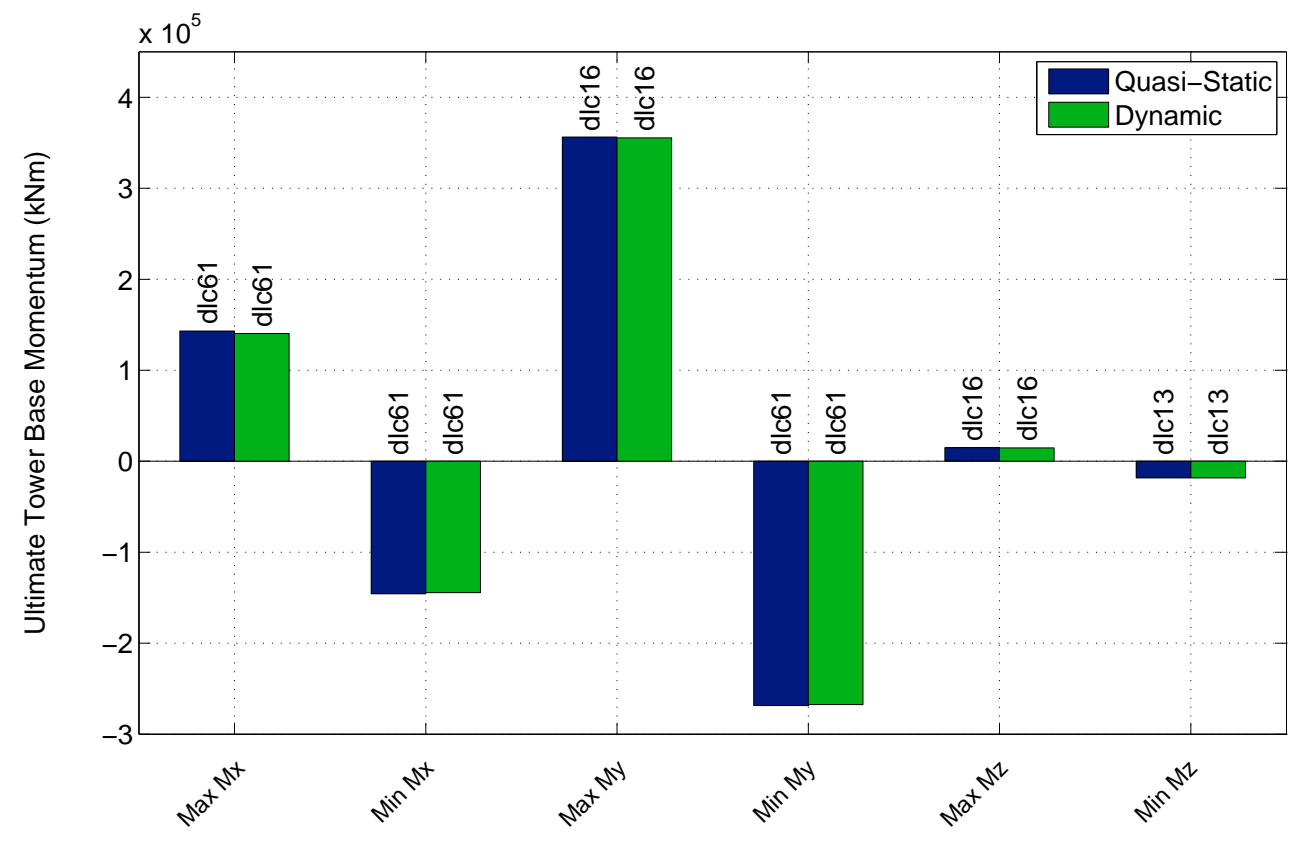

Figure 26. Ultimate loads at tower base for the spar platform 


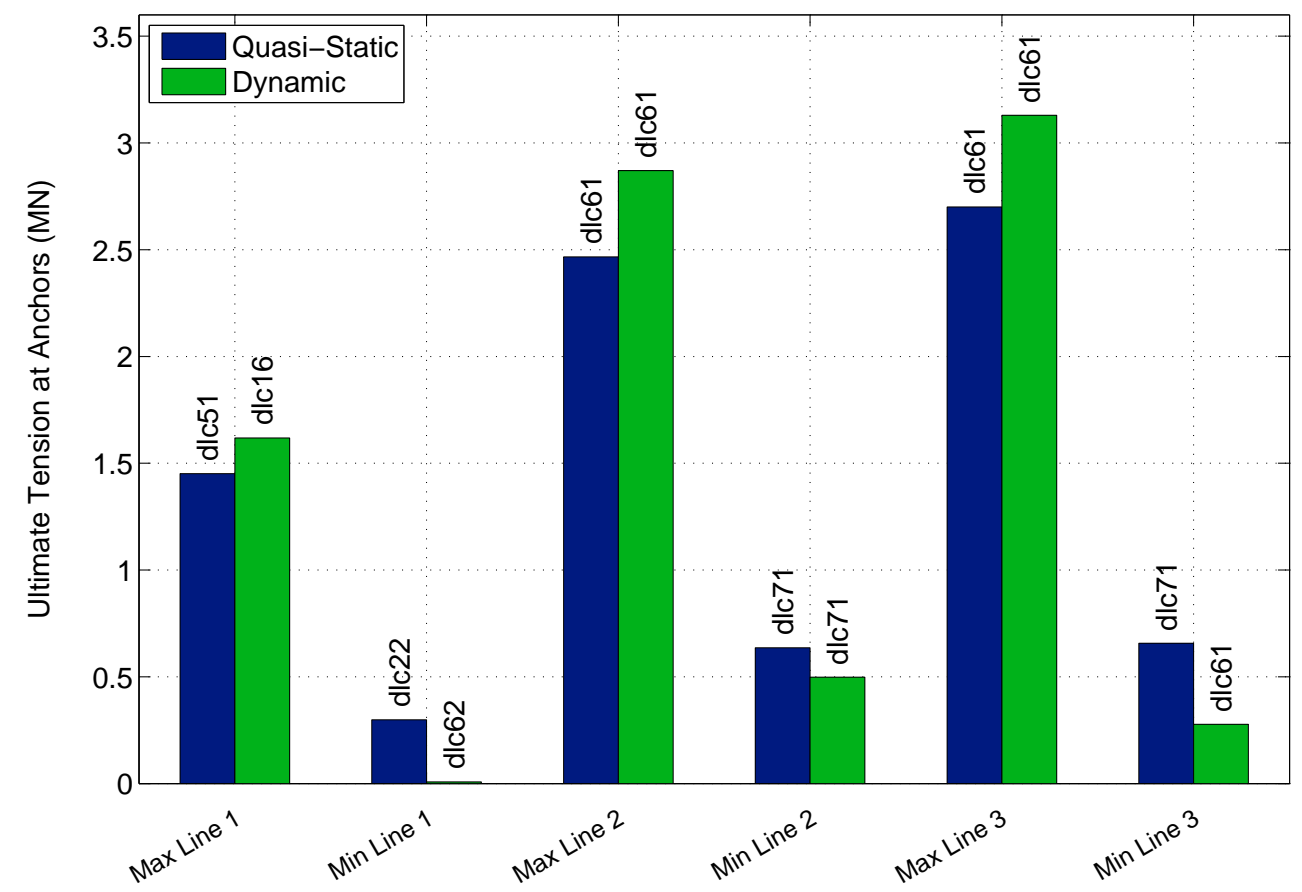

Figure 27. Ultimate tension at the lines anchors for the spar platform

\subsection{OC4 DeepCwind semisubmersible ultimate loads}

For the semisubmersible platform, the effect of the mooring dynamics in the ultimate loads of the wind turbine components is also low, see Figures 28 (blade root), 29 (low speed shaft) and 30 (tower). The only exception is the minimum $M_{y}$ component of the tower bending moment, increased around $20 \%$ in absolute value when dynamics are included.

The impact of the line dynamics in the line tension is important, producing an increment of the tension measured at the anchors. The increase of the maximum tension is $12 \%$ and $18 \%$ for the two downwind lines (lines 1 and 3 , respectively) and $42 \%$ for the upwind line (line 2) which has the highest mean tension. The mooring dynamics also produce a decrease of the tension minimum values. In particular, for the line 2 , the dynamic model predicts a lose of tension in the line that is not captured by the Quasi-Static approach. 


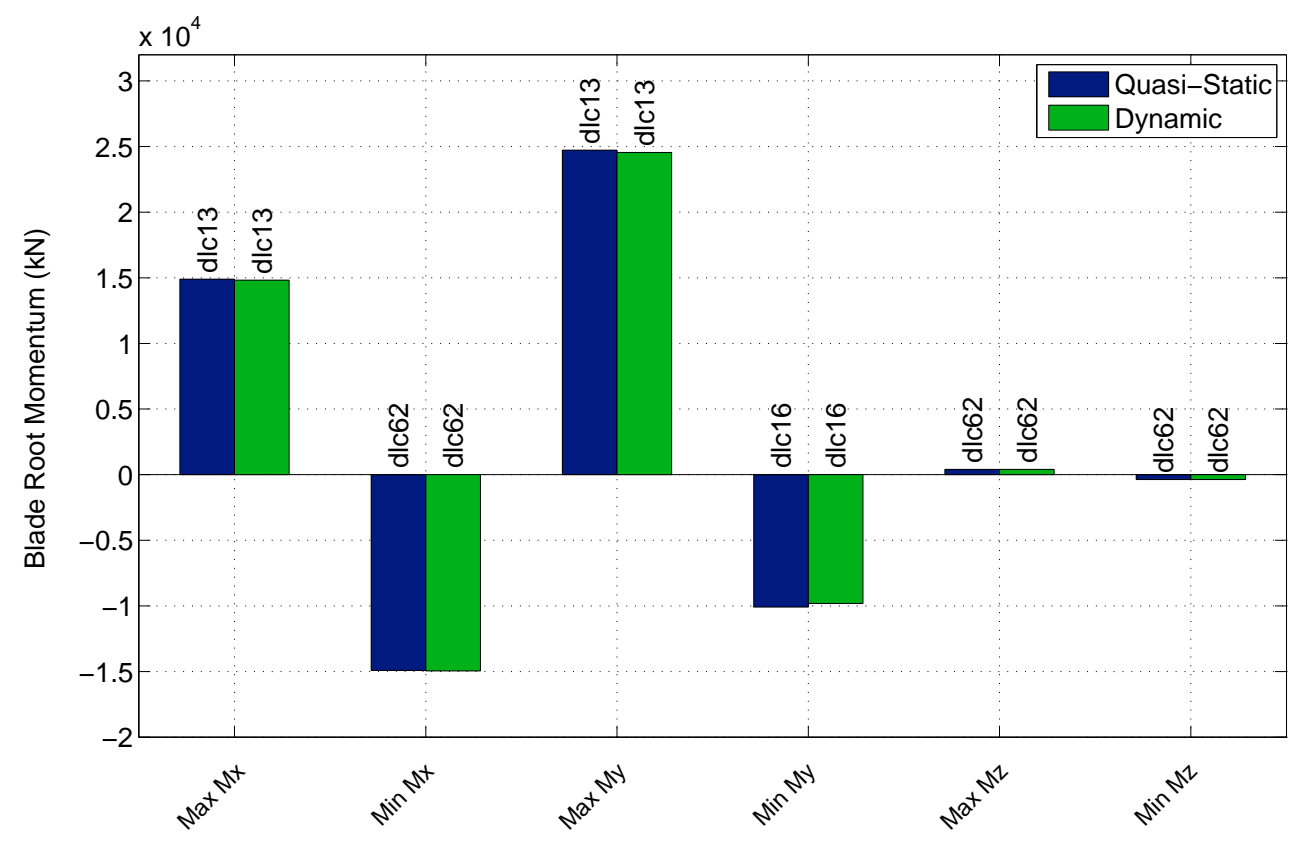

Figure 28. Ultimate loads at blade root for the semisubmersible platform

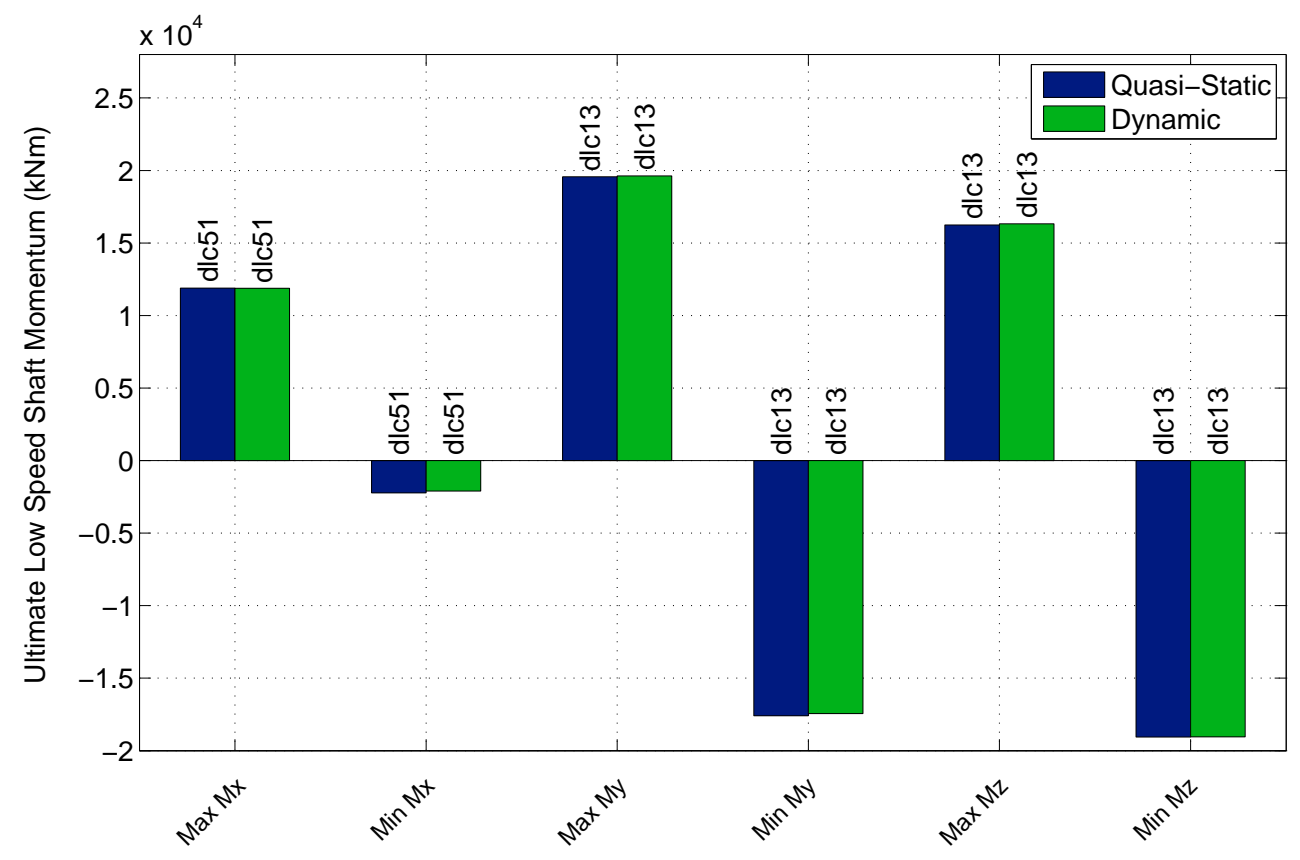

Figure 29. Ultimate loads at the low speed shaft for the semisubmersible platform 


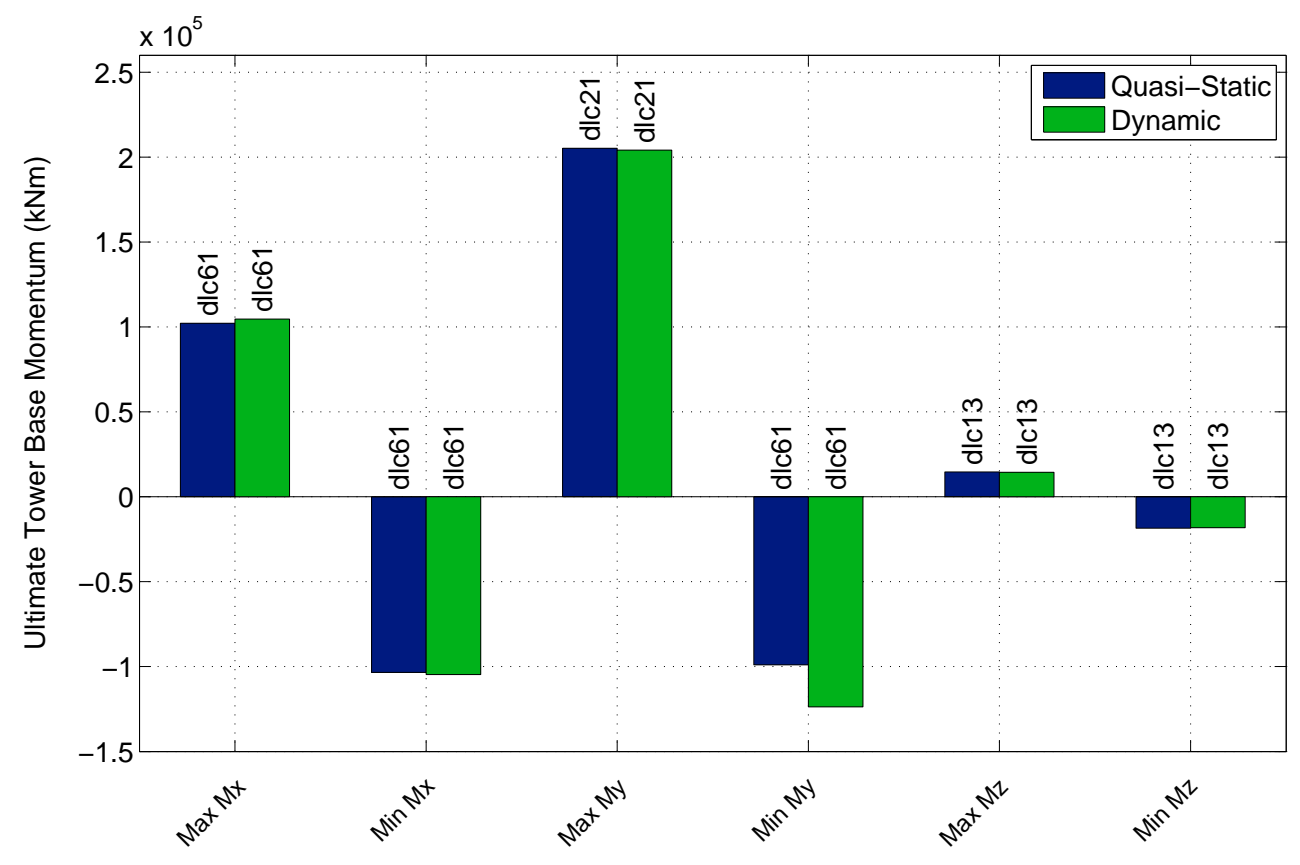

Figure 30. Ultimate loads at tower base for the semisubmersible platform

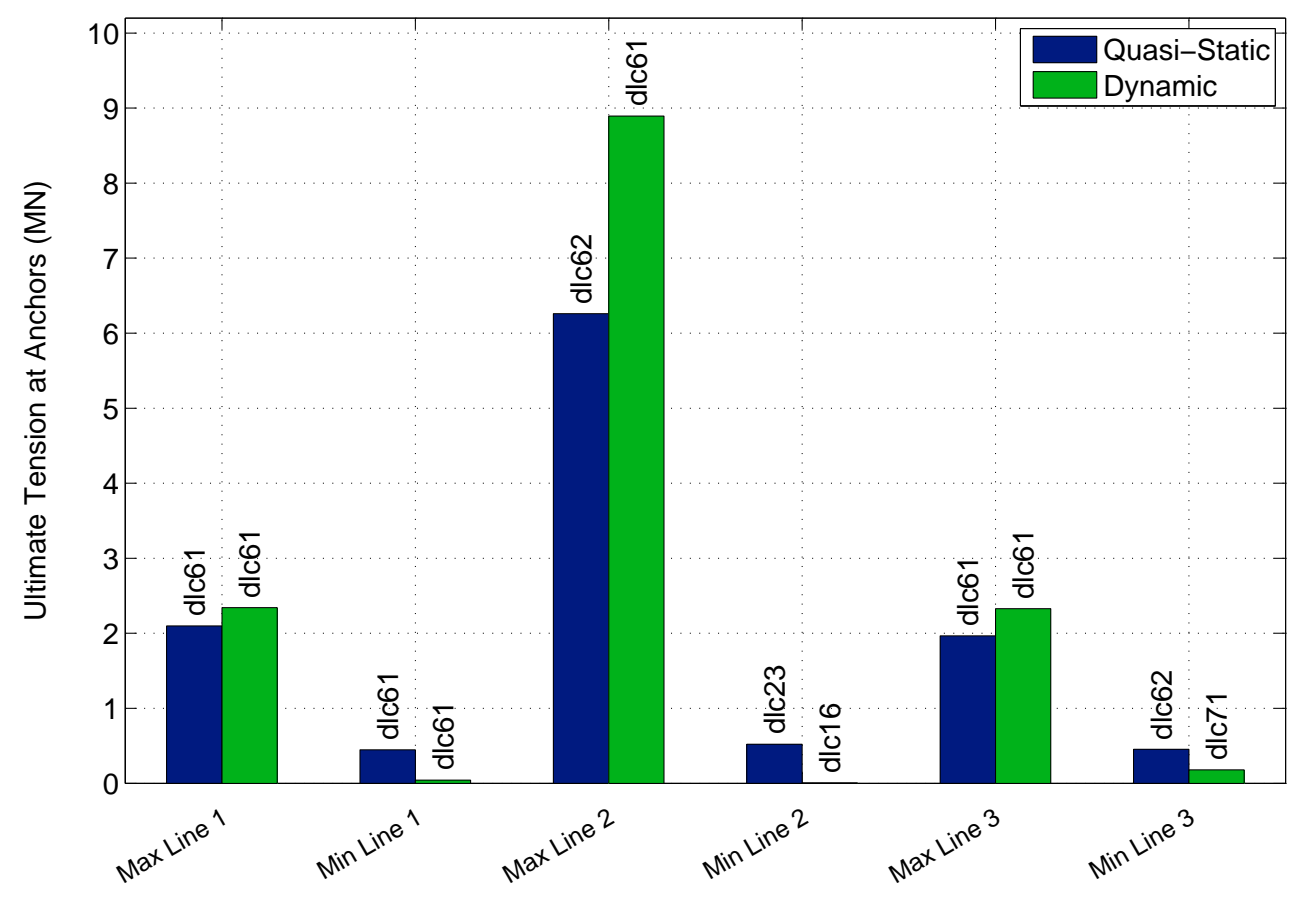

Figure 31. Ultimate tension at the lines anchors for the semisubmersible platform 


\subsection{UMaine TLP ultimate loads}

The influence of the mooring lines dynamics on the ultimate loads of the wind turbine components is more relevant for the TLP than in the other two platforms. For the blade root, differences between the loads provided with the Quasi-Static and the dynamic models are moderate and without a clear tendency, see Figure 32. For the maximum loads, all the differences are below $2 \%$. Regarding the negative values of the moments, the dynamic model increases $5 \%$ the absolute value of $M_{x}$, but decreases $8 \%$ the absolute value of the $M_{y}$ component compared to the Quasi-Static.

The ultimate loads at the low speed shaft are compared in Figure 33. The dynamic and Quasi-Static models provide similar loads, with differences below $1 \%$, with the exception of the negative value of the torsional moment $M_{x}$, being the value provided by the dynamic model one fifth of the Quasi-Static.

The loads at the tower base, showed in Figure 34, are the most affected by the dynamic model. The damping of the pitch and roll motions of the platform by the dynamic model is reflected in an important decrease of the maximum bending moments at the tower base. This decrease is around $34 \%$ for the $M_{x}$ component and $24 \%$ for the $M_{y}$ component.

Finally, Figure 35 shows that the extreme tension at the lines is also decreased if the dynamic model is used. Once more the drag of the lines damps the platform motions, reducing the tension of the lines. The inertial effects in the TLP lines are low because the high stiffness of the taut mooring system avoids high accelerations of the platform even in the hard environmental conditions defined for the ultimate cases. The reduction in the maximum tension is between $25 \%$ (lines 1 and 2) and 45\% (line 3). Both models predict the loss of tension of the lines 1 and 3. For the line 2 (in the upwind direction), the Quasi-Static model also predicts a loss of tension, but the dynamic model provides a minimum tension of $1072 \mathrm{kN}$.

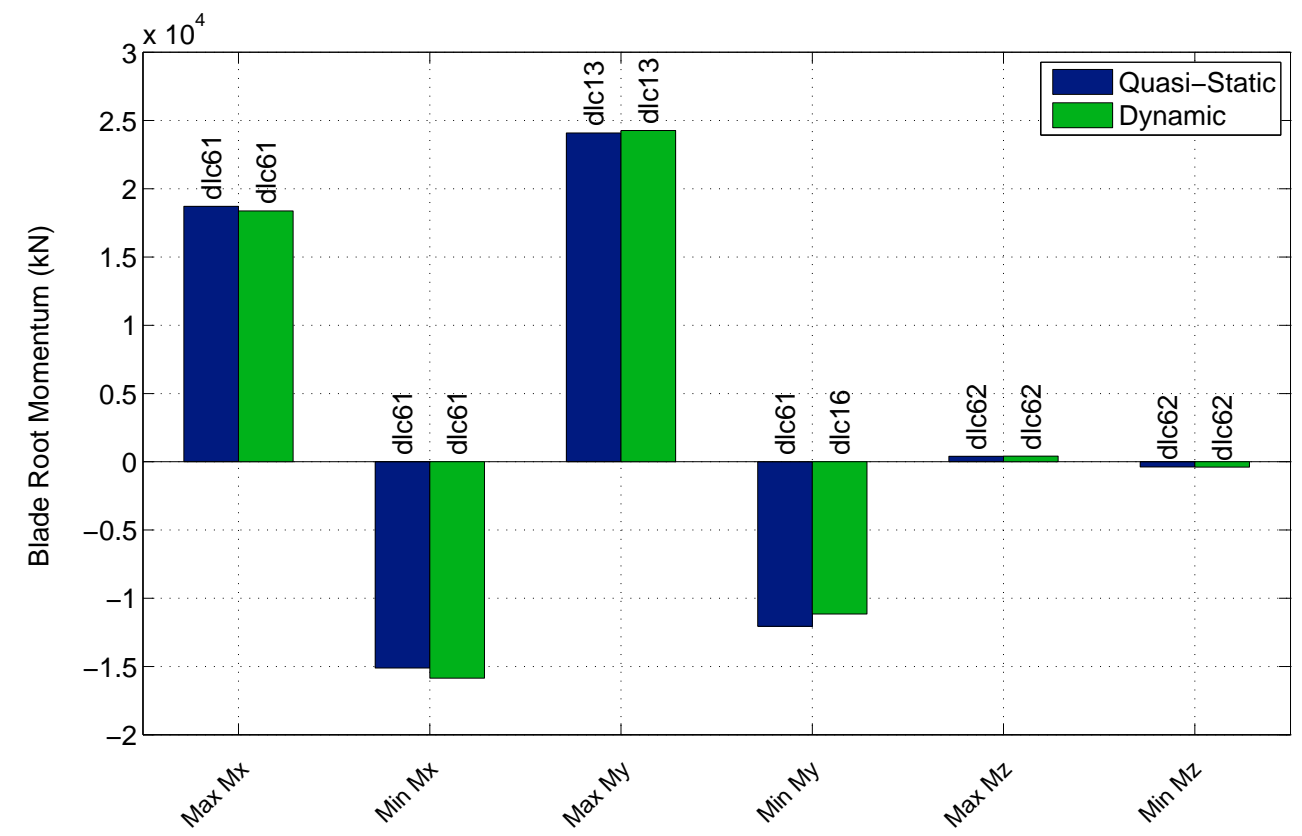

Figure 32. Ultimate loads at blade root for the TLP platform 


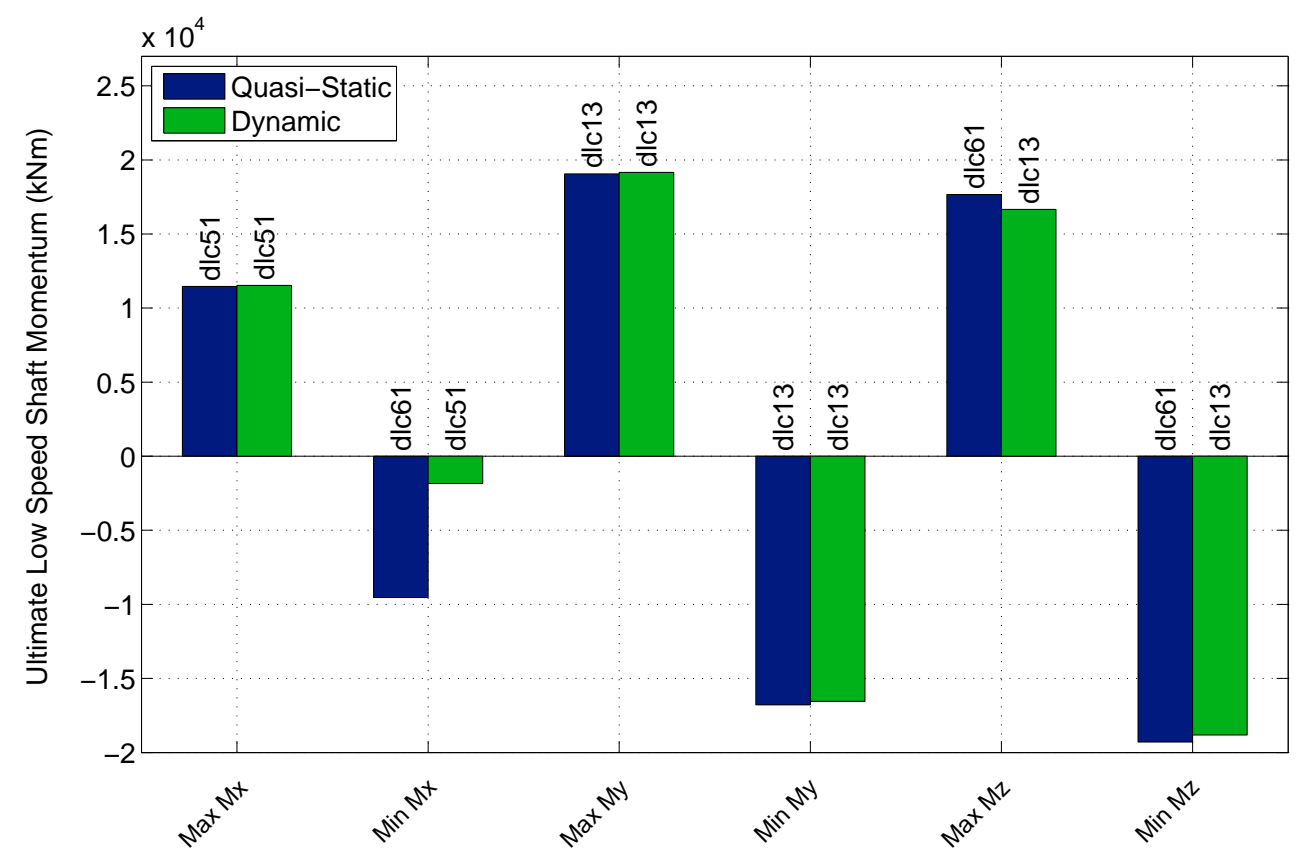

Figure 33. Ultimate loads at the low speed shaft for the TLP platform

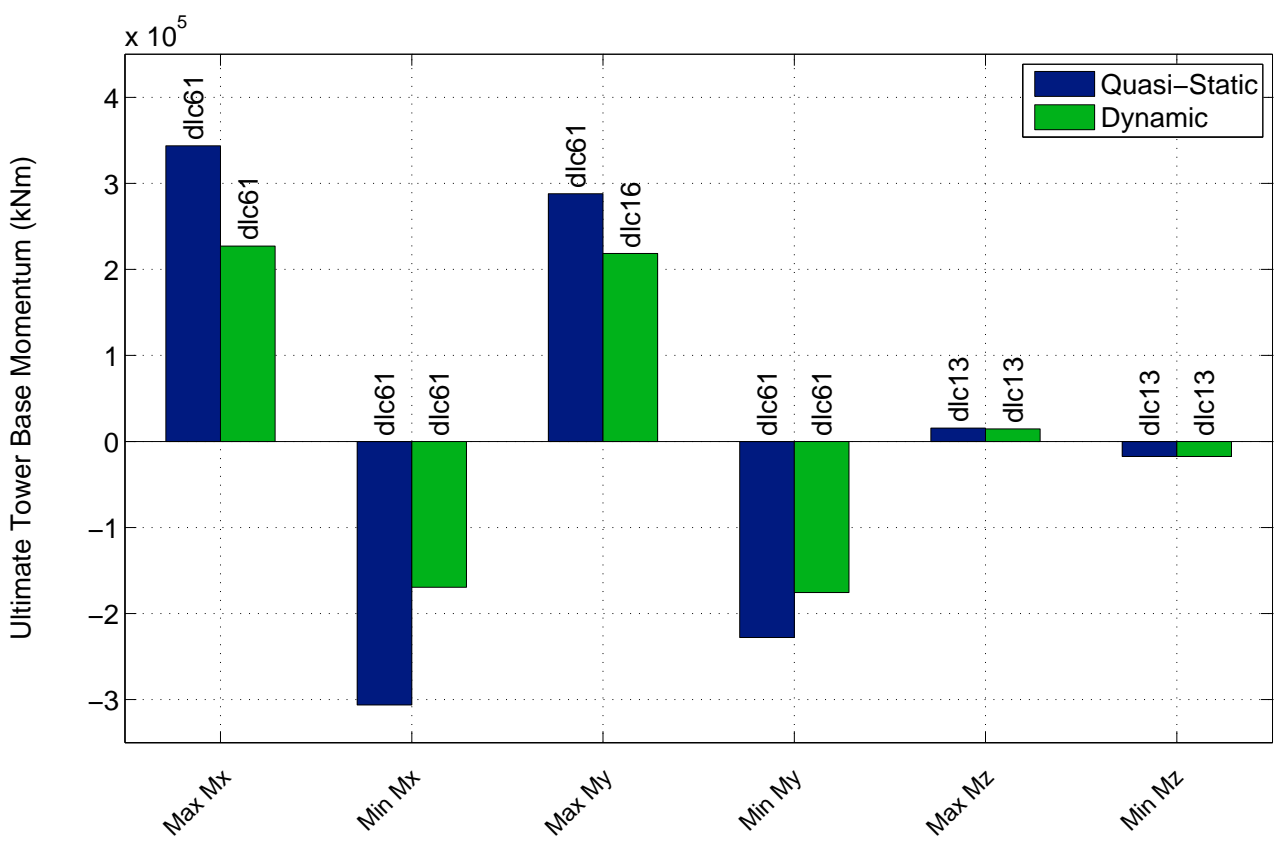

Figure 34. Ultimate loads at tower base for the TLP platform 


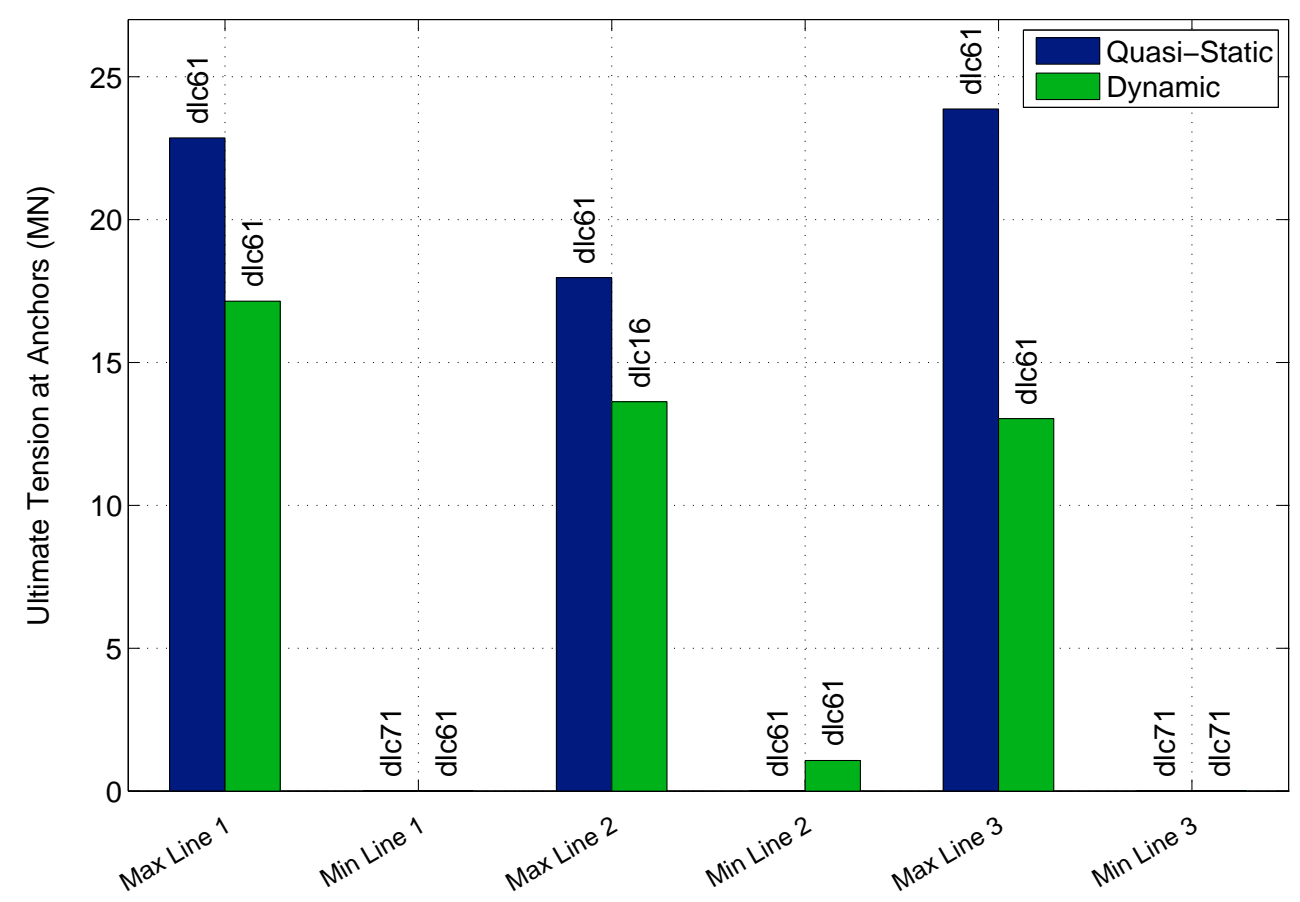

Figure 35. Ultimate tension at the lines anchors for the TLP platform

\subsection{Summary of the effect of mooring lines dynamics on the ultimate loads of the three platforms}

The relative differences between the ultimate loads computed using the Quasi-Static model and the dynamic model are compared in this Section for the three platforms. For the calculation of the differences, the absolute value of the maximum and minimum load of each component has been considered. A positive value of the relative differences corresponds to higher ultimate loads calculated with the dynamic model and negative differences correspond to lower loads calculated with the dynamic model, in comparison with the Quasi-Static.

Figures 36 and 37 show that the effect in the ultimate loads introduced by the dynamic model are not relevant for the blade root and the shaft in any of the platforms, having differences always below $2.5 \%$.

Figure 38 reveals that the bending moments at the tower base are considerably affected by the lines dynamics in the TLP platform. The $M_{x}$ and $M_{y}$ components are decreased $34 \%$ and $24 \%$ respectively when compared with the Quasi-Static. In the spar and semisubmersible platforms the line dynamics affects much less the tower base moments with maximum differences between both models lower than $2 \%$.

Regarding the lines maximum tensions, Figure 39 shows that the effect is important for the three designs. In the case of the spar, the use of the dynamic mooring lines model increases the maximum tension in the lines between $11 \%$ and $15 \%$. For the semisubmersible, the increase is higher, up to $42 \%$ for the upwind line. On the other hand, the moorings dynamics produces an important decrease in the line tension for the TLP platform. In this concept with taut mooring lines, the inertial effects have lower importance and the drag of the dynamic approach reduces the amplitude of the platform motions resulting in a reduction of the maximum tension in the lines between $25 \%$ and $45 \%$. 


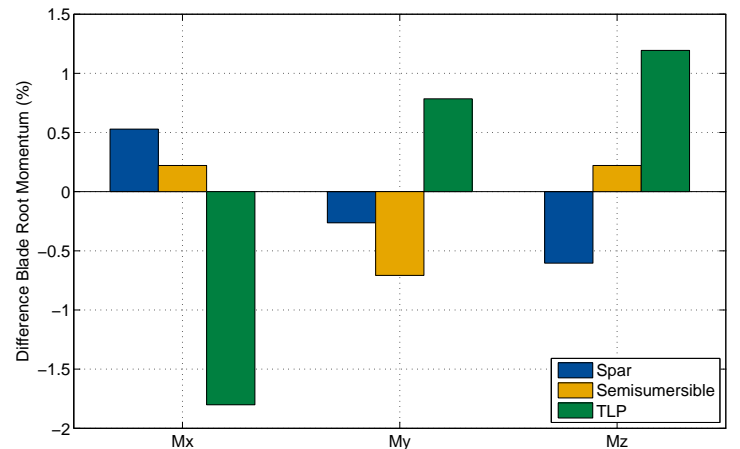

Figure 36. Differences in the blade ultimate loads computed with moorings dynamics compared with Quasi-Static

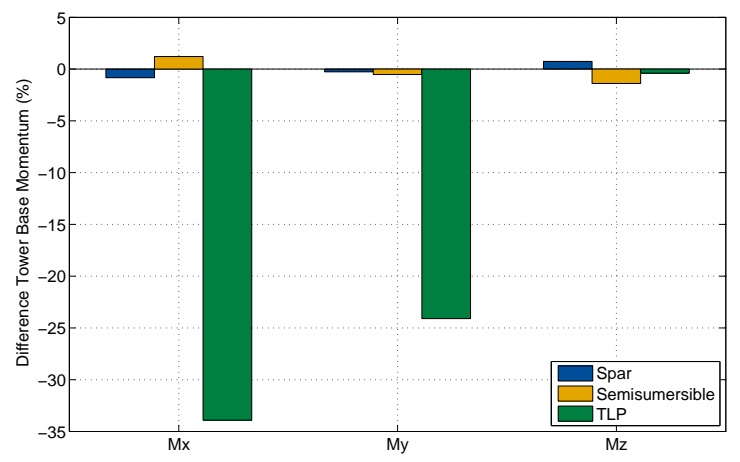

Figure 38. Differences in the tower base ultimate loads computed with moorings dynamics compared with Quasi-Static

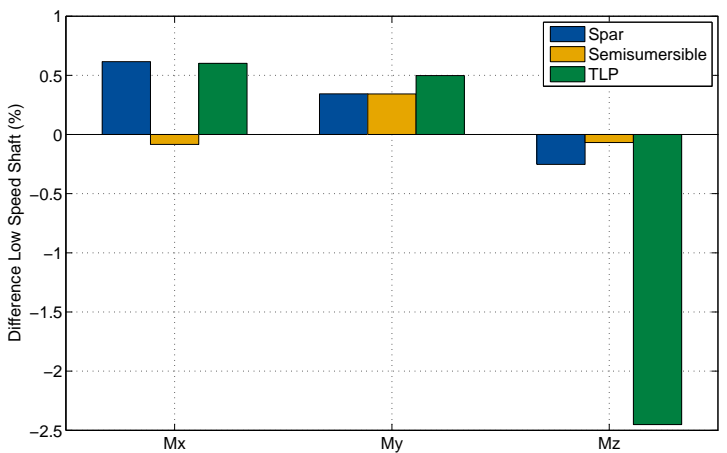

Figure 37. Differences in the shaft ultimate loads computed with moorings dynamics compared with Quasi-Static

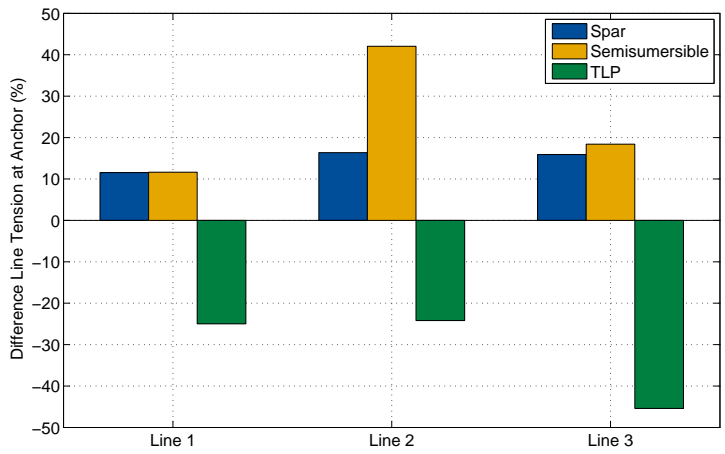

Figure 39. Differences in the lines anchor ultimate tension computed with moorings dynamics compared with Quasi-Static

\subsection{Importance of the DLC's groups on the ultimate loads}

An overview of the importance of the load case groups in the ultimate loads is given in this subsection, though a deeper analysis will be done in future work. The group of cases providing each ultimate load has benn indicated in the plots of the ultimate loads (Figures 24 to 35 ).

The group of cases DLC 6.1 is driving a large number of extreme loads. In particular, it always determines the maximum tension at the anchor lines for all the platforms, with the exception of the maximum tension at the semisubmersible with the Quasi-Static mooring model, given by DLC 6.2. In addition, DLC 6.1 determines the maximum $M_{x}$ component of the blade root moment for the spar and the TLP and the maximum $M_{x}$ component of the tower base moment for the three platforms.

DLC 1.3 has also great importance, marking the extreme shaft bending moment in the three platform concepts and the blade root bending moment for the semisubmersible ( $M_{x}$ and $M_{y}$ components) and the TLP ( $M_{y}$ component). It also provides the extreme torsional moment of the tower for the three platforms.

DLC 1.6 is particularly relevant for the spar platform, where it is responsible of the extreme loads for the blade $M_{y}$, the shaft $M_{z}$ and the tower $M_{y}$ components of the bending moments. For the TLP it also determines the maximum tower base $M_{y}$ moment with the dynamic model.

Finally, DLC 5.1 provides the maximum torsional moment at the shaft for all the platform designs and DLC 2.1 provides the maximum $M_{y}$ component of the tower base moment for the semisubmersible. 


\section{CONCLUSIONS}

A comprehensive study on the influence of mooring line dynamics on the calculation of wind turbine loads following the standard certification requirements for the wind energy industry has been presented.

Three different platform designs (spar, semisubmersible and TLP) were studied to characterize the effect of the mooring dynamics over each concept. The loads were computed following the methodology and the cases defined by the IEC 61400-3 Edition 1 guideline, which implied the computation and postprocessing of more than 20,000 simulation cases. The fatigue and ultimate loads obtained for each platform design using a Quasi-Static moorings model and a dynamic moorings model were compared.

The impact of using a dynamic model for the mooring system in the results provided by integrated simulation codes depends on the typology of the floating platform and the component considered.

In general, the influence of mooring dynamics in both fatigue and ultimate loads increases as elements located closer to the platform are evaluated; the blade and the shaft loads are only slightly modified by the mooring dynamics in all the platform designs, the tower base loads can be significantly affected depending on the platform concept, and the mooring lines tensions strongly depend on the lines dynamics both in fatigue and extreme loads in all the platform concepts evaluated.

The equivalent fatigue tension at the anchors of the three platform designs are impacted by the moorings dynamics, but the effect can be very different depending on the platform considered. For the semisubmersible, that presents the heave natural period inside the wave spectrum, dynamics can increase the equivalent tension up to $57 \%$. For the spar and the TLP, the equivalent tensions are moderately decreased (up to $8 \%$ ) when dynamics are introduced.

For the spar platform, the effect of mooring dynamics on the fatigue of the wind turbine components (blades, shaft and tower) is very low due to the little influence of the mooring system over the pitch and roll motions. For the semisubmersible and the TLP moorings dynamics introduce a significant decrease the fatigue of the wind turbine components, in particular for the tower.

Regarding ultimate loads, mooring dynamics cannot be neglected for the calculation of the extreme line tensions in any of the three platforms studied. Including mooring dynamics in the integrated simulations can have diverse effects on the extreme line tensions depending on the platform type, with an increase (semisubmersible) or decrease (TLP) of more than $40 \%$ with respect to the Quasi-Static.

Mooring dynamics are very important for the calculation of the tower base ultimate loads in the TLP design, where the extreme moments are decreased between $24 \%$ and $34 \%$. For the other platforms and wind turbine elements, the effect on the ultimate loads is much more limited.

As a final remark, our study reveals that mooring dynamics has the greatest impact in the computation of:

- Fatigue equivalent tensions and ultimate tensions of the mooring lines in any platform configuration

- In particular, fatigue equivalent tensions of the moorings for platforms with natural frequencies inside the wave spectrum, which are strongly increased

- Fatigue and ultimate loads of the components of wind turbines supported by TLP platforms

- Tower base fatigue loads for platforms with fairleads located at a long radius from the platform center

\section{ACKNOWLEDGMENTS}

We want to thank Amy Robertson for her kind assistance providing and building the FAST floating wind turbine models. We also want to acknowledge our colleagues from CENER Elena Cantero, for her help in the site selection and for calculating the environmental wind and wave conditions, and Joseba Garciandía and Alfredo Martínez for their work developing the scripts for setting and launching the load cases. The major part of this work has been funded by the European Community's IRPWind project, under grant agreement number 609795. The research has also received funding from the Spanish Ministry for Science and Innovation under grant TRA2013-41096-P "Optimization of liquid gas transport for LNG vessels by fluid structure interaction studies".

1. Masciola M, Robertson A N, Jonkman J M, Driscoll F. 2011. Investigation of a FAST-OrcaFlex Coupling Module for Integrating Turbine and Mooring Dynamics of Offshore Floating Wind Turbines, in: International Conference on Offshore Wind Energy and Ocean Energy, Beijing, China.

2. Jonkman J M. 2007. Dynamics Modeling and Loads Analysis of an Offshore Floating Wind Turbine. PhD Thesis, University of Colorado, USA. 
3. Lindahl J, Sjøberg A. 1983. Dynamic Analysis of Mooring Cales, in: International Symposium on Ocean Engineering and Ship Handling, vol 2, pp. 281-319.

4. Hall M, Buckham B, Crawford C. 2014. Evaluating the Importance of Mooring Line Model Fidelity in Floating Offshore Wind Turbine Simulations. Wind Energy Vol 17(12), pp. 18351853.

5. Kallesøe B S, Hansen A M. 2011. Dynamic Mooring Line Modeling in Hydro-Aero-Elastic Wind Turbine Simulations, in: International Offshore and Polar Engineering Conference, ISOPE 2011, Maui, Hawaii, USA.

6. Matha D, Fechter U, Kühn M, Cheng P W. 2011. Non-linear Multi-Body Mooring System Model for Floating Offshore Wind Turbines, in: EWEA Offshore 2011, Amsterdam, The Netherlands.

7. Masciola M, Robertson A N, Jonkman J M, Coulling A, Goupee A. 2013. Assessment of the Importance of Mooring Dynamics on the Global Response of the DeepCWind Floating Semisubmersible Offshore Wind Turbine, in: Proceedings of the 23th International Conference on Offshore and Polar Engineering, pp. 359-368, Anchorage, Alaska, USA.

8. IEC. 2009. IEC 61400-3 Ed. 1.0 Wind turbines - Design requirements for offshore wind turbines.

9. Azcona J, Munduate X, Nygaard T A, Merino D. 2011. Development of OPASS Code for Dynamic Simulation of Mooring Lines in Contact with Seabed, in: EWEA Offshore 2011, Amsterdam, The Netherlands.

10. De Vaal J B, Nygaard T A. 2015. 3DFloat User Manual. Report IFE/KR/E-2015-001. Institute for Energy Technology, Norway

11. Robertson A N, Jonkman J M, Vorpahl F, Wojciech P, Qvist J, Frøyd L, Chen X, Azcona J, Uzunoglu E, Guedes Soares C, Luan C, Yutong H, Pengcheng F, Yde A, Larsen T, Nichols J, Buils R, Lei L, Nygaard T A, Manolas D, Heege A, Vatne S R, Ormberg H, Duarte T, Godreau C, Hansen H F, Nielsen A W, Riber H, Le Cunff C, Beyer F, Yamaguchi A, Jung K J, Shin H, Shi W, Park H, Alves M, Guérinel M. 2014. Offshore Code Comparison Collaboration Continuation within IEA Wind Task 30: Phase II Results Regarding a Floating Semisubmersible Wind System, in: 33rd International Conference on Ocean, Offshore and Arctic Engineering, OMAE, San Francisco, USA.

12. Jonkman J M. 2010. Definition of the floating system for phase IV of OC3. Technical Report NREL/TP-500-47535, National Renewable Laboratory (NREL), Golden (CO), USA.

13. Robertson A N, Jonkman J M, Masciola M, Song H, Goupee A, Coulling A, Luan C. 2014. Definition of the Semisubmersible Floating System for Phase II of OC4. Technical Report TP-5000-60601, National Renewable Laboratory (NREL), Golden (CO), USA.

14. Stewart G, Lackner M, Goupee, A. 2012. Calibration and Validation of a FAST Floating Wind Turbine Model of the DeepCwind Scaled Tension-Leg Platform, in: Proceedings of the 22nd International Conference on Offshore and Polar Engineering, Rhodes, Greece.

15. Jonkman J M, Butterfield S, Musial W, Scott G. 2009. Definition of a 5-MW Reference Wind Turbine for Offshore System Development. Technical Report NREL/TP-500-38060, National Renewable Laboratory (NREL), Golden (CO), USA.

16. Robertson A N, Jonkman J M. 2011. Loads Analysis of Several Offshore Floating Wind Turbine Concepts, in: International Offshore and Polar Engineering Conference, ISOPE 2011, Maui, Hawaii, USA.

17. Goupee A J, Koo B J, Lambrakos K F, Kimball R W. 2012. Model Tests for Three Floating Wind Turbine Concepts, in: Offshore Technology Conference (OTC 2012), Houston, Texas, USA.

18. Moon III W L, Nordstrom C J. 2010. Tension leg platform turbine: A unique integration of mature technologies, in: Proceedings of the 16th Offshore Symposium (Section of the Society of Naval Architects and Marine Engineers), Houston, Texas.

19. Bureau Veritas. 2002. NR 493 R02 E, Classification of Mooring Systems for Permanent Offshore Units.

20. DNV. 2013. DNV OS E301 Position Mooring - DNV offshore Standards Det Norske Veritas, Høvik, Norway.

21. Kallos G. 1997. The Regional weather forecasting system SKIRON, in: Proceedings Symposium on Regional Weather Prediction on Parallel Computer Environments, p. 9, Athens, Greece.

22. Hasselmann S, Hasselmann K, Bauer E, Janssen P A E M, Komen G J, Bertotti L, Lionello P, Guillaume A, Cardone V C, Greenwood J A, Reistad M, Zambresky J A. 1988. The WAM model - A third generation ocean wave prediction model. Journal of Physical Oceanography, vol 18, pp. 1775-1810.

23. GL. 2010. Guideline for the Certification of Wind Turbines Edition 2010. Germanischer Lloyd Industrial Services GmbH, Hamburg, Germany. 